\title{
Similarity Of Effects On EEG And HRV Parameters Of Aramaic, Greek Catholic And Krishnaic Prayers
}

\author{
Igor L. Popovych ${ }^{1,6}$, Anatoliy I. Gozhenko ${ }^{1}$, Valeriy Ye. Babelyuk ${ }^{2}$, Walery Zukow ${ }^{3}$, \\ Radosław Muszkieta ${ }^{3}$, Tetyana A. Korolyshyn' ${ }^{2}$, Galyna I. Dubkova ${ }^{2}$, Ivan M. Klishch ${ }^{4}$, \\ Igor R. Mysula ${ }^{4}$, Volodymyra R. Bilas ${ }^{2}$, Igor-Severyn S. Flyunt ${ }^{5}$, Vitaliy M. Fil'5, \\ Liliya G. Barylyak ${ }^{1}$ \\ ${ }^{1}$ Ukrainian Scientific Research Institute of Medicine for Transport, Odesa, Ukraine \\ prof.gozhenko@gmail.com \\ ${ }^{2}$ Clinical Sanatorium „Moldova”, Truskavets', Ukraine san.moldova.tr@ukr.net \\ ${ }^{3}$ Nicolaus Copernicus University, Torun, Poland w.zukow@wp.pl \\ ${ }^{4}$ Ivan Horbachevs'kyi National Medical University, Ternopil', Ukraine \\ ${ }^{5}$ Ivan Franko Pedagogical University, Drohobych, Ukraine \\ ${ }^{6}$ Kozyavkin International Rehabilitation Clinic, Truskavets', Ukraine \\ i.popovych@biph.kiev.ua
}

\begin{abstract}
Background.

Results. The neurotropic effects of Prayer are manifested in two inhibitory and three activating patterns. The first inhibitory pattern reflects the decrease in elevated and upper limit levels of SPD of $\theta$-and $\delta$-rhythm in frontal loci and the second - decrease in normal SPD levels of $\beta$-and $\theta$-rhythm in the frontal, central, temporal and parietal loci. The first activating pattern reflects a small increase in normal levels of $\beta$-rhythm index and asymmetry and SPD entropy in locus $\mathrm{C} 3$, as well as a further increase in elevated $\delta$-rhythm SPD levels in loci P3 and T3. The second pattern reflects the slight increase in normal SPD levels of $\theta$-rhythm in loci T3, T5, T6, O2 and $\alpha$-rhythm in locus T5, as well as their indices and entropy SPD in locus O2. The third pattern reflects a slight increase in amplitude and SPD of $\alpha$-rhythm in central, frontal, temporal and occipital loci.
\end{abstract}

Key words: Prayers; Aramaic, Greek Catholic; Krishnaic.

\section{MATERIAL AND METHODS}

The object of observation were 4 men: Greek Catholic priest Father Volodymyr, head of the Church Brotherhood Ivan, a supporter of Krishna Victor, and your obedient servant, the first author to memorize the authentic Lord's Prayer in Aramaic. December 25, 2015 in the morning in basale terms at first registered (GI Dubkova) kirlianogram by the method of gasdischarge visualization (GDV) by the device "GDV Chamber" ("Biotechprogress", St-Pb, RF). For further analysis the following parameters were selected: Area, Coefficient of Shape as ratio Square Length of outward contour gas discharge image to its Area as well as Entropy of contour in Right, Frontal and Left projections registered both with and without poliethylene filter. Estimated also Energy and Asymmetry of virtual Chakras.

Than recorded (TA Korolyshyn) for 7 minutes electrocardiogram in II lead to assess the parameters of heart rate variability (HRV) (software-hardware complex "CardioLab+HRV" production "KhAI-MEDICA", Kharkiv, Ukraine) and simultaneously four times for 25 seconds electroencephalogram (with eyes closed) (hardware-software complex "NeuroCom Standard", KhAI MEDICA). 
For further analysis the following parameters HRV were selected. Temporal parameters (Time Domain Methods): the standart deviation of all NN intervals (SDNN), the square root of the mean of the sum of the squares of differences between adjacent NN intervals (RMSSD), the percent of interval differences of successive $\mathrm{NN}$ intervals greater then $50 \mathrm{~ms}\left(\mathrm{pNN}_{50}\right)$ as well as Triangulary Index (TINN). Spectral parameters (Frequency Domain Methods): spectral power density (SPD) of HRV bands: high-frequency ( $\mathrm{HF}$, range $0,4 \div 0,15 \mathrm{~Hz}$ ), lowfrequency ( $\mathrm{LF}$, range $0,15 \div 0,04 \mathrm{~Hz}$ ), very low-frequency (VLF, range $0,04 \div 0,015 \mathrm{~Hz}$ ) and ultra low-frequency (ULF, range $0,015 \div 0,003 \mathrm{~Hz}$ ) []. Baevskiy's parameters: heart rate (HR), mode (Mo), the amplitude of mode (AMo), variational sweep (MxDMn). Based on these parameters, the indices were calculated: $\mathrm{LF} / \mathrm{HF}$ ratio, $\mathrm{LFnu}=100 \% \cdot \mathrm{LF} /(\mathrm{LF}+\mathrm{HF})$, Centralization Index (VLF+LF)/HF), Stress Index (AMo/2・Mo $\bullet \mathrm{MxDMn})$ as well as Activity Regulatory Systems Index (BARSI) [1].

EEG recorded monopolar in 16 loci (Fp1, Fp2, F3, F4, F7, F8, C3, C4, T3, T4, P3, P4, T5, $\mathrm{T} 6, \mathrm{O} 1, \mathrm{O} 2)$ by 10-20 international system, with the reference electrodes A and Ref on the tassels ears. Among the options considered the average EEG amplitude $(\mu \mathrm{V})$, average frequency $(\mathrm{Hz})$, frequency deviation $(\mathrm{Hz})$, index $(\%)$, coefficient of asymmetry $(\%)$ and absolute $\left(\mu \mathrm{V}^{2} / \mathrm{Hz}\right)$ and relative (\%) SPD of basic rhythms: $\beta(35 \div 13 \mathrm{~Hz}), \alpha(13 \div 8 \mathrm{~Hz}), \theta(8 \div 4$ $\mathrm{Hz})$ and $\delta(4 \div 0,5 \mathrm{~Hz})$ in all loci, according to the instructions of the device. In addition, calculated Laterality Index (LI) for SPD each Rhythm using formula:

LI, $\%=\Sigma[200 \bullet($ Right - Left $) /($ Right + Left $)] / 8$

We calculated also for HRV and each locus of EEG the Entropy (h) of normalized SPD using formulas [] based on classical CE Shannon's formula:

hHRV $=-\left[S P D H F \bullet \log _{2} S P D H F+S P D L F \bullet \log _{2} S P D L F+S P D V L F \bullet \log _{2} S P D V L F+S P D U L F \bullet \log _{2} S P D U L F\right] / \log _{2} 4$

$\mathrm{hEEG}=-\left[\mathrm{SPD} \alpha \bullet \log _{2} \mathrm{SPD} \alpha+\mathrm{SPD} \beta \bullet \log _{2} \mathrm{SPD} \beta+\mathrm{SPD} \theta \bullet \log _{2} \mathrm{SPD} \theta+\mathrm{SPD} \delta \bullet \log _{2} \mathrm{SPD} \delta\right] / \log _{2} 4$

After initial testing, ECG and EEG (4-7 times for 25 seconds) was again registered for the next 7 minutes. At the same time, the participants of the study silently said a Prayer: Father Volodymyr and Brother Ivan "Our Father ...", benefactor Victor in Sanskrit "Hare Krishna ...", and the author in Aramaic "Oh, breathing Life, your Name shines everywhere ...". After that, the kirlianogram was re-registered. To be quite precise, the first three autoexperiments was conducted in advance, and its results inspired the author to repeat it.

Results processed using the software package "Statistica 5.5".

\section{RESULTS AND DISCUSSION}

This article analyzes only the parameters of EEG and HRV, while the parameters of GDV will be the subject of further research. The reason for this separation is not the limited size of the article at all, but the hostile attitude of Ukrainian academic science to the GDV method (thank God, although atheism has long since lost its official status).

The neurotropic effect of Prayer was assessed by the following algorithm. We first calculated the average of four 25 -second basal recordings taken over 7 minutes. The direct differences between 4-7 recordings taken during the next 7-minute Prayer and the basal level were then determined. Finally, we calculated the average, which was considered a measure of the effect of Prayer on a particular EEG parameter.

Table 1 contains parameters whose changes are statistically significant $(p \leq 0,05)$. Retrospectively, Entropy SPD in locus $\mathrm{O} 2$ was also included, which unexpectedly appeared in the structure of the discriminant model.

Pseudo-coloring is used for the convenience of visual perception of information ( $\delta$ rhythm, $\boldsymbol{\theta}$-rhythm, $\boldsymbol{\alpha}$-rhythm, $\boldsymbol{\beta}$-rhythm as well as Entropy). 
Table 1. EEG Variables, their Means and Changes caused by Prayer. Parameters are ranked by direct differences of $\mathrm{Z}$-score (see following table)

\begin{tabular}{|c|c|c|c|c|}
\hline \multirow[b]{2}{*}{ Variables } & \multirow{2}{*}{$\begin{array}{c}\text { Reference } \\
\text { level } \\
(88)\end{array}$} & \multicolumn{2}{|c|}{ Mean \pm SE } & \multirow{2}{*}{$\begin{array}{c}\text { Difference, } \\
\text { Mean } \pm \text { SE } \\
\text { (36) }\end{array}$} \\
\hline & & $\begin{array}{l}\text { Baseline } \\
(28)\end{array}$ & $\begin{array}{l}\text { Prayer } \\
(36)\end{array}$ & \\
\hline T3- $\theta$ SPD, \% & $8,4 \pm 0,4$ & $7,4 \pm 0,7$ & $10,1 \pm 1,1$ & $+2,1 \pm 0,7$ \\
\hline T6- $\theta$ SPD, \% & $6,5 \pm 0,3$ & $4,3 \pm 0,95$ & $6,5 \pm 1,1$ & $+1,5 \pm 0,6$ \\
\hline Entropy SPD in locus T6 & $0,74 \pm 0,02$ & $0,44 \pm 0,06$ & $0,57 \pm 0,06$ & $+0,07 \pm 0,02$ \\
\hline Entropy SPD in locus C3 & $0,83 \pm 0,01$ & $0,85 \pm 0,02$ & $0,89 \pm 0,01$ & $+0,04 \pm 0,01$ \\
\hline T3- $\delta$ SPD, \% & $20,2 \pm 1,4$ & $57,6 \pm 3,9$ & $60,6 \pm 3,3$ & $+5,2 \pm 2,6$ \\
\hline P3- $\delta$ SPD, \% & $19,8 \pm 1,3$ & $49,7 \pm 3,2$ & $53,7 \pm 3,0$ & $+4,9 \pm 2,2$ \\
\hline$\beta$-rhythm Asymmetry, \% & $19,8 \pm 1,5$ & $22,4 \pm 3,9$ & $28,6 \pm 3,9$ & $+5,3 \pm 1,5$ \\
\hline$\alpha$-rhythm Index, \% & $49,9 \pm 3,3$ & $28,1 \pm 3,7$ & $34,9 \pm 3,8$ & $+10,3 \pm 2,8$ \\
\hline T5- $\theta$ SPD, $\%$ & $7,3 \pm 0,4$ & $5,6 \pm 1,0$ & $7,7 \pm 1,3$ & $+1,3 \pm 0,6$ \\
\hline O2- $\theta$ SPD, $\%$ & $4,9 \pm 0,3$ & $4,9 \pm 0,8$ & $6,5 \pm 0,9$ & $+0,9 \pm 0,4$ \\
\hline C3- $\alpha$ SPD, \% & $41,8 \pm 2,0$ & $17,8 \pm 1,1$ & $22,6 \pm 1,3$ & $+5,5 \pm 1,1$ \\
\hline F4- $\alpha$ SPD, \% & $40,9 \pm 2,1$ & $13,9 \pm 1,5$ & $18,4 \pm 1,5$ & $+5,4 \pm 1,0$ \\
\hline C4-a SPD, \% & $41,6 \pm 1,9$ & $17,5 \pm 1,5$ & $20,8 \pm 1,3$ & $+4,6 \pm 1,4$ \\
\hline T6- $\alpha$ SPD, \% & $38,0 \pm 2,4$ & $6,9 \pm 1,1$ & $13,5 \pm 1,9$ & $+5,4 \pm 1,1$ \\
\hline F3- $\alpha$ SPD, \% & $41,9 \pm 2,1$ & $15,0 \pm 1,2$ & $18,9 \pm 1,6$ & $+4,5 \pm 1,1$ \\
\hline$\beta$-rhythm Index, \% & $87,9 \pm 1,9$ & $94,4 \pm 1,2$ & $97,0 \pm 0,5$ & $+3,5 \pm 1,1$ \\
\hline$\theta$-rhythm Index, $\%$ & $25,2 \pm 4,5$ & $17,7 \pm 3,5$ & $26,2 \pm 3,6$ & $+8,5 \pm 3,6$ \\
\hline Fp2- $\alpha$ SPD, \% & $39,8 \pm 2,1$ & $10,5 \pm 0,9$ & $13,5 \pm 1,7$ & $+3,8 \pm 1,3$ \\
\hline T4- $\alpha$ SPD, \% & $38,1 \pm 2,1$ & $6,7 \pm 0,7$ & $10,9 \pm 1,3$ & $+3,7 \pm 1,9$ \\
\hline T5- $\alpha$ SPD, $\mu \mathrm{V}^{2} / \mathrm{Hz}$ & $134 \pm 16$ & $68 \pm 8$ & $102 \pm 14$ & $+26 \pm 11$ \\
\hline O2- $\alpha$ SPD, $\%$ & $54,5 \pm 2,6$ & $12,6 \pm 1,6$ & $17,7 \pm 2,1$ & $+3,6 \pm 1,2$ \\
\hline T5- $\alpha$ SPD, \% & $36,8 \pm 2,3$ & $9,6 \pm 1,1$ & $13,5 \pm 1,8$ & $+3,0 \pm 1,1$ \\
\hline C4-a SPD, $\mu \mathrm{V}^{2} / \mathrm{Hz}$ & $202 \pm 19$ & $55 \pm 3$ & $72 \pm 6$ & $+16 \pm 6$ \\
\hline F4- $\alpha$ SPD, $\mu \mathrm{V}^{2} / \mathrm{Hz}$ & $179 \pm 16$ & $46 \pm 2$ & $60 \pm 5$ & $+13 \pm 4$ \\
\hline$\alpha$-rhythm Amplitude, $\mu \mathrm{V}$ & $22,1 \pm 1,5$ & $10,3 \pm 0,3$ & $11,5 \pm 0,6$ & $+1,1 \pm 0,5$ \\
\hline Entropy SPD in locus $\mathrm{O2}$ & $0,69 \pm 0,02$ & $0,57 \pm 0,06$ & $0,64 \pm 0,05$ & $+0,01 \pm 0,01$ \\
\hline P4- $\beta$ SPD, $\%$ & $25,5 \pm 1,8$ & $17,2 \pm 2,3$ & $16,2 \pm 1,7$ & $-3,0 \pm 1,5$ \\
\hline C3- $\beta$ SPD, \% & $27,2 \pm 1,7$ & $24,2 \pm 1,9$ & $20,7 \pm 1,0$ & $-3,2 \pm 1,3$ \\
\hline C4- $\beta$ SPD, $\%$ & $27,4 \pm 1,7$ & $21,7 \pm 1,7$ & $18,7 \pm 1,2$ & $-3,0 \pm 1,3$ \\
\hline F3- $\beta$ SPD, \% & $26,3 \pm 1,7$ & $17,0 \pm 1,6$ & $14,4 \pm 1,0$ & $-3,5 \pm 1,3$ \\
\hline$\beta$-rhythm Laterality, \% & $-8 \pm 3$ & $-36 \pm 6$ & $-40 \pm 6$ & $-6,2 \pm 3,1$ \\
\hline P4- $\theta$ SPD,$\mu V^{2} / H z$ & $35,5 \pm 2,7$ & $41,5 \pm 2,9$ & $37,8 \pm 3,7$ & $-5,9 \pm 2,8$ \\
\hline P3- $\beta$ SPD, \% & $27,4 \pm 1,9$ & $21,0 \pm 1,8$ & $17,7 \pm 1,3$ & $-4,4 \pm 1,2$ \\
\hline F8- $\beta$ SPD, $\mu V^{2} / \mathrm{Hz}$ & $69 \pm 7$ & $47 \pm 12$ & $36 \pm 7$ & $-22 \pm 11$ \\
\hline F4- $\theta$ SPD, $\mu \mathrm{V}^{2} / \mathrm{Hz}$ & $38,7 \pm 2,6$ & $37,1 \pm 4,7$ & $34,9 \pm 3,2$ & $-7,3 \pm 2,4$ \\
\hline F7- $\beta$ SPD, $\mu V^{2} / H z$ & $77 \pm 9$ & $68 \pm 12$ & $55 \pm 6$ & $-26 \pm 9$ \\
\hline$\theta$-rhythm Laterality, \% & $-5 \pm 3$ & $-11 \pm 7$ & $-25 \pm 7$ & $-10 \pm 3$ \\
\hline T4- $\beta$ SPD, \% & $31,3 \pm 1,9$ & $16,4 \pm 3,0$ & $12,0 \pm 1,5$ & $-7,6 \pm 1,9$ \\
\hline$\beta$-rhythm Deviation, $\mathrm{Hz}$ & $1,29 \pm 0,08$ & $1,48 \pm 0,12$ & $1,14 \pm 0,10$ & $-0,32 \pm 0,14$ \\
\hline C4- $\beta$ SPD,$\mu \mathrm{V}^{2} / \mathrm{Hz}$ & $88 \pm 5$ & $74 \pm 9$ & $63 \pm 5$ & $-20 \pm 8$ \\
\hline T3- $\beta$ SPD, $\%$ & $34,1 \pm 1,9$ & $21,3 \pm 2,6$ & $14,7 \pm 1,7$ & $-8,5 \pm 1,8$ \\
\hline C4- $\theta$ SPD, $\mu V^{2} / H z$ & $38,3 \pm 2,5$ & $44 \pm 7$ & $39 \pm 5$ & $-11 \pm 3$ \\
\hline$\delta$-rhythm Asymmetry, \% & $32,8 \pm 2,8$ & $38,8 \pm 3,1$ & $27,5 \pm 1,7$ & $-13,3 \pm 3,5$ \\
\hline Fp1- $\beta$ SPD, $\mu V^{2} / H z$ & $66,5 \pm 3,4$ & $64,5 \pm 8,9$ & $56,4 \pm 4,6$ & $-17,0 \pm 6,9$ \\
\hline C3- $\beta$ SPD,$\mu V^{2} / \mathrm{Hz}$ & $96 \pm 5$ & $85 \pm 11$ & $66 \pm 4$ & $-28 \pm 9$ \\
\hline $\mathrm{C} 3-\delta \mathrm{SPD}, \mu \mathrm{V}^{2} / \mathrm{Hz}$ & $95 \pm 9$ & $183 \pm 21$ & $155 \pm 16$ & $-49 \pm 14$ \\
\hline F3- $\delta$ SPD, $\mu \mathrm{V}^{2} / \mathrm{Hz}$ & $95 \pm 10$ & $347 \pm 35$ & $301 \pm 31$ & $-56 \pm 24$ \\
\hline F3- $\beta$ SPD, $\mu V^{2} / \mathrm{Hz}$ & $86 \pm 5$ & $82 \pm 11$ & $62 \pm 4$ & $-31 \pm 8$ \\
\hline T6- $\beta$ SPD, $\mu V^{2} / \mathrm{Hz}$ & $93 \pm 8$ & $114 \pm 28$ & $94 \pm 22$ & $50 \pm 22$ \\
\hline T3- $\beta$ SPD, $\mu V^{2} / \mathrm{Hz}$ & $103 \pm 10$ & $108 \pm 21$ & $65 \pm 7$ & $-67 \pm 14$ \\
\hline F4- $\beta$ SPD, $\mu V^{2} / \mathrm{Hz}$ & $76 \pm 4$ & $75 \pm 10$ & $60 \pm 6$ & $-25 \pm 8$ \\
\hline T4- $\beta$ SPD, $\mu V^{2} / \mathrm{Hz}$ & $80 \pm 6$ & $95 \pm 21$ & $51 \pm 8$ & $-65 \pm 13$ \\
\hline
\end{tabular}




\begin{tabular}{|l|l|l|l|l|}
\hline Fp2- $\boldsymbol{\theta}$ SPD, $\boldsymbol{\mu} \mathbf{V}^{2} / \mathbf{H z}$ & $21,8 \pm 1,5$ & $49 \pm 7$ & $41 \pm 4$ & $-17 \pm 5,5$ \\
\hline F4- $\mathbf{S P D}, \boldsymbol{\mu \mathbf { V } ^ { 2 } / \mathbf { H z }}$ & $89 \pm 19$ & $324 \pm 49$ & $234 \pm 29$ & $-126 \pm 32$ \\
\hline $\mathbf{F p 2}-\boldsymbol{\delta} \mathbf{S P D}, \boldsymbol{\mu} \mathbf{V}^{2} / \mathbf{H z}$ & $110 \pm 25$ & $902 \pm 281$ & $559 \pm 124$ & $-571 \pm 256$ \\
\hline F8- $\boldsymbol{\theta}$ SPD, $\boldsymbol{\mu} \mathbf{V}^{2} / \mathbf{H z}$ & $12,5 \pm 0,9$ & $60 \pm 15$ & $47 \pm 7$ & $-24 \pm 10$ \\
\hline
\end{tabular}

At the next stage of the analysis, the actual values (V) were translated into Z-score (Table 2) by the formula:

\section{$\mathrm{Z}=(\mathrm{V}-\mathrm{N}) / \sigma_{\mathrm{N}}=(\mathrm{V} / \mathrm{N}-1) / \mathrm{Cv}$, where}

$\mathrm{N}$ - normal (reference) level of the parameter, borrowed from the database of Truskavet'sian

Scientific School;

$\sigma_{\mathrm{N}}-$ standard deviation;

$\mathrm{Cv}$ - variability coefficient

Table 2. Z-scores of EEG Variables and their Changes caused by Prayer

\begin{tabular}{|c|c|c|c|c|}
\hline \multirow[b]{2}{*}{ Variables } & \multirow[b]{2}{*}{$\begin{array}{l}\text { Variability } \\
\text { coefficients }\end{array}$} & \multicolumn{2}{|c|}{ Z-score $\pm \mathrm{SE}$} & \multirow{2}{*}{$\begin{array}{c}\text { Difference, } \\
\mathrm{Z} \pm \mathrm{SE} \\
(36)\end{array}$} \\
\hline & & $\begin{array}{l}\text { Baseline } \\
(28)\end{array}$ & $\begin{array}{l}\text { Prayer } \\
(36)\end{array}$ & \\
\hline T3-0 SPD, $\%$ & 0,390 & $-0,29 \pm 0,21$ & $+0,53 \pm 0,35$ & $+0,65 \pm 0,21$ \\
\hline T6- $\theta$ SPD, \% & 0,477 & $-0,71 \pm 0,31$ & $0,00 \pm 0,35$ & $+0,48 \pm 0,18$ \\
\hline Entropy SPD in locus T6 & 0,199 & $-2,02 \pm 0,38$ & $-1,14 \pm 0,40$ & $+0,44 \pm 0,14$ \\
\hline Entropy SPD in locus C3 & 0,114 & $+0,30 \pm 0,16$ & $+0,66 \pm 0,15$ & $+0,42 \pm 0,15$ \\
\hline T3- $\delta$ SPD, $\%$ & 0,635 & $+2,92 \pm 0,30$ & $+3,15 \pm 0,26$ & $+0,41 \pm 0,20$ \\
\hline P3- $\delta$ SPD, $\%$ & 0,620 & $+2,43 \pm 0,26$ & $+2,76 \pm 0,25$ & $+0,40 \pm 0,18$ \\
\hline$\beta$-rhythm Asymmetry, \% & 0,717 & $+0,18 \pm 0,28$ & $+0,62 \pm 0,28$ & $+0,38 \pm 0,11$ \\
\hline$\alpha$-rhythm Index, \% & 0,625 & $-0,70 \pm 0,12$ & $-0,48 \pm 0,13$ & $+0,33 \pm 0,09$ \\
\hline T5- $\theta$ SPD, \% & 0,548 & $-0,42 \pm 0,26$ & $+0,09 \pm 0,32$ & $+0,32 \pm 0,15$ \\
\hline O2-0 SPD, $\%$ & 0,559 & $-0,02 \pm 0,29$ & $+0,58 \pm 0,34$ & $+0,32 \pm 0,16$ \\
\hline C3- $\alpha$ SPD, \% & 0,449 & $-1,28 \pm 0,06$ & $-1,02 \pm 0,07$ & $+0,30 \pm 0,06$ \\
\hline F4- $\alpha$ SPD, \% & 0,470 & $-1,41 \pm 0,08$ & $-1,17 \pm 0,08$ & $+0,28 \pm 0,05$ \\
\hline C4- $\alpha$ SPD, \% & 0,439 & $-1,32 \pm 0,08$ & $-1,14 \pm 0,07$ & $+0,25 \pm 0,07$ \\
\hline T6- $\alpha$ SPD, \% & 0,602 & $-1,36 \pm 0,05$ & $-1,07 \pm 0,08$ & $+0,24 \pm 0,05$ \\
\hline F3- $\alpha$ SPD, \% & 0,469 & $-1,37 \pm 0,06$ & $-1,17 \pm 0,08$ & $+0,23 \pm 0,06$ \\
\hline$\beta$-rhythm Index, $\%$ & 0,197 & $+0,38 \pm 0,07$ & $+0,53 \pm 0,03$ & $+0,20 \pm 0,06$ \\
\hline$\theta$-rhythm Index, \% & 1,679 & $-0,18 \pm 0,08$ & $+0,02 \pm 0,08$ & $+0,20 \pm 0,09$ \\
\hline Fp2- $\alpha$ SPD, \% & 0,492 & $-1,49 \pm 0,05$ & $-1,34 \pm 0,09$ & $+0,19 \pm 0,06$ \\
\hline T4- $\alpha$ SPD, \% & 0,512 & $-1,61 \pm 0,03$ & $-1,39 \pm 0,07$ & $+0,19 \pm 0,05$ \\
\hline T5- $\alpha$ SPD, $\mu V^{2} / H z$ & 1,136 & $-0,44 \pm 0,05$ & $-0,21 \pm 0,09$ & $+0,17 \pm 0,07$ \\
\hline O2- $\alpha$ SPD, \% & 0,453 & $-1,70 \pm 0,06$ & $-1,49 \pm 0,09$ & $+0,15 \pm 0,05$ \\
\hline T5- $\alpha$ SPD, \% & 0,580 & $-1,28 \pm 0,05$ & $-1,09 \pm 0,08$ & $+0,14 \pm 0,05$ \\
\hline C4- $\alpha$ SPD, $\mu V^{2} / H z$ & 0,871 & $-0,84 \pm 0,02$ & $-0,74 \pm 0,04$ & $+0,09 \pm 0,04$ \\
\hline F4- $\alpha$ SPD, $\mu V^{2} / H z$ & 0,864 & $-0,86 \pm 0,02$ & $-0,77 \pm 0,03$ & $+0,08 \pm 0,03$ \\
\hline$\alpha$-rhythm Amplitude, $\boldsymbol{\mu V}$ & 0,657 & $-0,81 \pm 0,02$ & $-0,73 \pm 0,04$ & $+0,08 \pm 0,03$ \\
\hline Entropy SPD in locus $\mathrm{O2}$ & 0,261 & $-0,67 \pm 0,31$ & $-0,28 \pm 0,30$ & $+0,07 \pm 0,08$ \\
\hline P4- $\beta$ SPD, \% & 0,649 & $-0,50 \pm 0,14$ & $-0,56 \pm 0,10$ & $-0,18 \pm 0,09$ \\
\hline C3- $\beta$ SPD, $\%$ & 0,573 & $-0,19 \pm 0,12$ & $-0,41 \pm 0,07$ & $-0,20 \pm 0,08$ \\
\hline C4- $\beta$ SPD, $\%$ & 0,583 & $-0,21 \pm 0,12$ & $-0,41 \pm 0,09$ & $-0,21 \pm 0,09$ \\
\hline F3- $\beta$ SPD, $\%$ & 0,609 & $-0,58 \pm 0,10$ & $-0,74 \pm 0,06$ & $-0,22 \pm 0,08$ \\
\hline$\beta$-rhythm Laterality, \% & $\sigma=27,1$ & $-1,03 \pm 0,24$ & $-1,19 \pm 0,21$ & $-0,23 \pm 0,11$ \\
\hline P4- $\theta$ SPD, $\mu V^{2} / \mathrm{Hz}$ & 0,716 & $+0,23 \pm 0,11$ & $+0,09 \pm 0,15$ & $-0,23 \pm 0,11$ \\
\hline P3- $\beta$ SPD, \% & 0,633 & $-0,37 \pm 0,10$ & $-0,56 \pm 0,08$ & $-0,25 \pm 0,07$ \\
\hline F8- $\beta$ SPD, $\mu V^{2} / H z$ & 1,165 & $-0,27 \pm 0,15$ & $-0,41 \pm 0,08$ & $-0,28 \pm 0,14$ \\
\hline F4- $\theta$ SPD, $\mu V^{2} / H z$ & 0,630 & $-0,06 \pm 0,19$ & $-0,15 \pm 0,13$ & $-0,30 \pm 0,10$ \\
\hline F7- $\beta$ SPD,$\mu V^{2} / H z$ & 1,083 & $-0,11 \pm 0,14$ & $-0,26 \pm 0,07$ & $-0,31 \pm 0,11$ \\
\hline$\theta$-rhythm Laterality, \% & $\sigma=27,6$ & $-0,20 \pm 0,25$ & $-0,72 \pm 0,25$ & $-0,36 \pm 0,12$ \\
\hline T4- $\beta$ SPD, $\%$ & 0,584 & $-0,81 \pm 0,16$ & $-1,06 \pm 0,08$ & $-0,42 \pm 0,10$ \\
\hline$\beta$-rhythm Deviation, $\mathrm{Hz}$ & 0,584 & $+0,26 \pm 0,16$ & $-0,20 \pm 0,13$ & $-0,43 \pm 0,19$ \\
\hline
\end{tabular}




\begin{tabular}{|c|c|c|c|c|}
\hline C4- $\beta$ SPD, $\mu V^{2} / H z$ & 0,479 & $-0,33 \pm 0,21$ & $-0,60 \pm 0,13$ & $-0,48 \pm 0,19$ \\
\hline T3- $\beta$ SPD, \% & 0,509 & $-0,74 \pm 0,15$ & $-1,12 \pm 0,10$ & $-0,49 \pm 0,10$ \\
\hline C4- $\theta$ SPD, $\mu V^{2} / \mathrm{Hz}$ & 0,611 & $+0,23 \pm 0,31$ & $+0,04 \pm 0,22$ & $-0,49 \pm 0,13$ \\
\hline$\delta$-rhythm Asymmetry, \% & 0,812 & $+0,22 \pm 0,12$ & $-0,20 \pm 0,06$ & $-0,50 \pm 0,13$ \\
\hline Fp1- $\beta$ SPD,$\mu V^{2} / H z$ & 0,484 & $-0,06 \pm 0,28$ & $-0,31 \pm 0,14$ & $-0,53 \pm 0,21$ \\
\hline C3- $\beta$ SPD,$\mu V^{2} / \mathrm{Hz}$ & 0,506 & $-0,22 \pm 0,22$ & $-0,62 \pm 0,08$ & $-0,58 \pm 0,19$ \\
\hline $\mathrm{C} 3-\delta \mathrm{SPD}, \mu \mathrm{V}^{2} / \mathrm{Hz}$ & 0,859 & $+1,08 \pm 0,26$ & $+0,74 \pm 0,20$ & $-0,60 \pm 0,18$ \\
\hline F3- $\delta$ SPD, $\mu V^{2} / \mathrm{Hz}$ & 0,989 & $+2,68 \pm 0,37$ & $+2,19 \pm 0,33$ & $-0,60 \pm 0,26$ \\
\hline F3- $\beta$ SPD, $\mu \mathrm{V}^{2} / \mathrm{Hz}$ & 0,558 & $-0,09 \pm 0,23$ & $-0,51 \pm 0,07$ & $-0,64 \pm 0,17$ \\
\hline T6- $\beta$ SPD, $\mu V^{2} / H z$ & 0,839 & $+0,27 \pm 0,36$ & $+0,01 \pm 0,29$ & $-0,65 \pm 0,29$ \\
\hline T3- $\beta$ SPD, $\mu V^{2} / H z$ & 0,895 & $+0,05 \pm 0,23$ & $-0,41 \pm 0,08$ & $-0,72 \pm 0,15$ \\
\hline F4- $\beta$ SPD, $\mu V^{2} / H z$ & 0,443 & $-0,03 \pm 0,29$ & $-0,48 \pm 0,19$ & $-0,73 \pm 0,23$ \\
\hline T4- $\beta$ SPD, $\mu V^{2} / \mathrm{Hz}$ & 0,702 & $+0,26 \pm 0,37$ & $-0,52 \pm 0,14$ & $-1,16 \pm 0,24$ \\
\hline Fp2- $\theta$ SPD,$\mu V^{2} / H z$ & 0,631 & $+1,99 \pm 0,51$ & $+1,36 \pm 0,29$ & $-1,24 \pm 0,40$ \\
\hline F4- $\delta$ SPD, $\mu V^{2} / H z$ & 0,994 & $+2,65 \pm 0,56$ & $+1,64 \pm 0,33$ & $-1,42 \pm 0,36$ \\
\hline Fp2- $\delta \mathrm{SPD}, \mu \mathrm{V}^{2} / \mathrm{Hz}$ & 2,162 & $+3,33 \pm 1,18$ & $+1,89 \pm 0,52$ & $-2,40 \pm 1,08$ \\
\hline F8- $\theta$ SPD, $\mu V^{2} / H z$ & 0,689 & $5,52 \pm 1,77$ & $4,00 \pm 0,77$ & $-2,81 \pm 1,19$ \\
\hline
\end{tabular}

Figure 1 shows that the significant inhibitory neurotropic effects of Prayer are more numerous than activating (30 parameters vs 26 ) and more pronounced (Mean $\pm \mathrm{SE}:-0,66 \pm 0,11$ vs $+0,27 \pm 0,3)$.
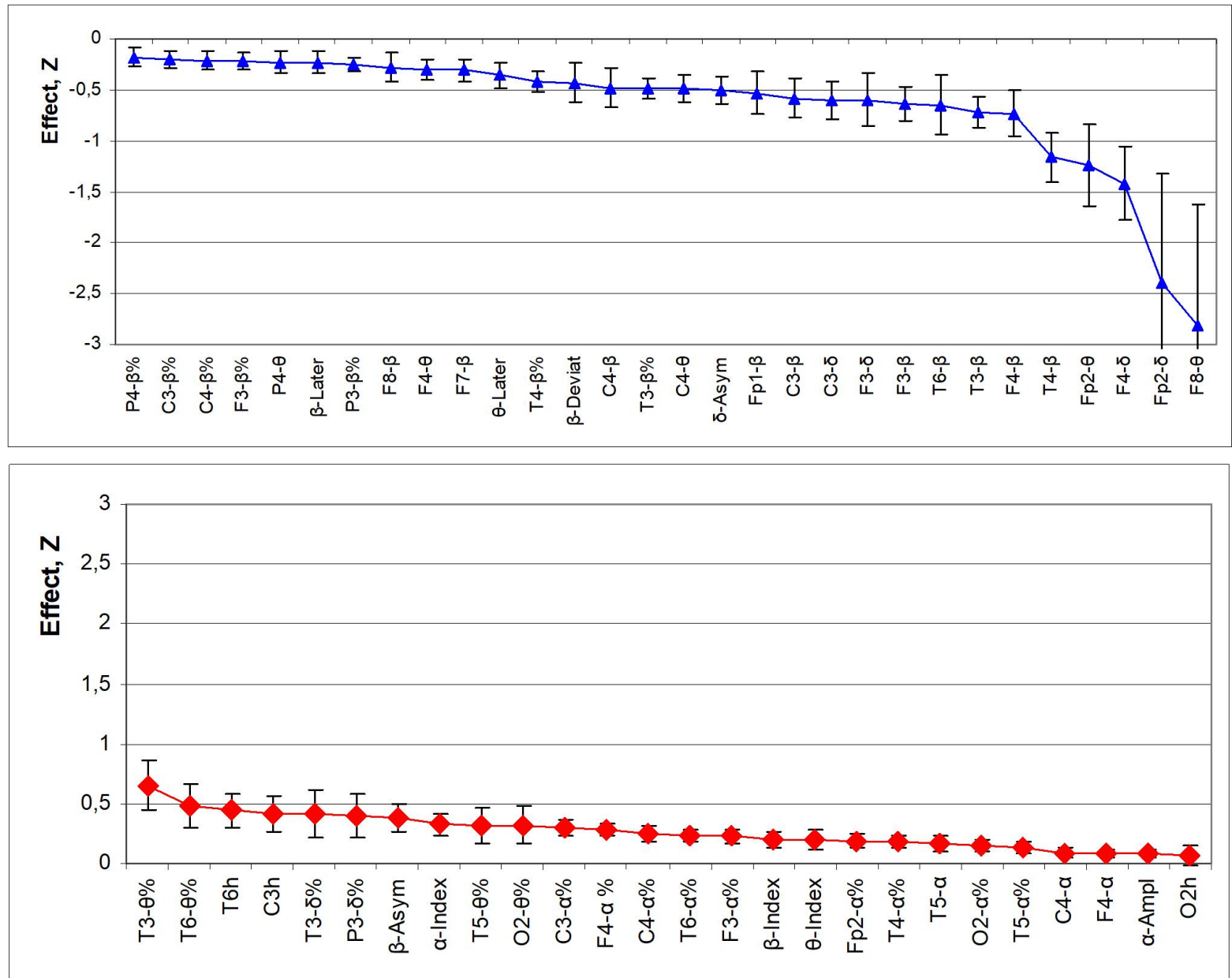

Fig. 1. Panoramic profiles of inhibitory (above) and activating (below) effects (Mean \pm SE) of Prayer on EEG parameters 
Therefore, further analysis will begin with inhibitory neurotropic effects. Based on the levels of parameters before and during Prayer and their changes, the inhibitory profile was divided into two patterns.

Assuming that the parameters in the range $-2 \sigma \div+2 \sigma$ are normal, we state that all four study participants are characterized by drastically elevated SPD of $\boldsymbol{\theta}$-rhythm in locus F8 and $\boldsymbol{\delta}$-rhythm in loci Fp2, F4, F3 (Fig. 2) as well as P3 and T3 (see Fig. 4).

Apparently, this is the result of many years of Prayer practice (by analogy with the influence of Meditation []). By the way, the first author since 2011 at least twice a day says "Our Father ..." in Ukrainian, Latin, Greek, German, English, Spanish, Italian, French, Polish and Russian, as well as an authentic Lord's Prayer in Aramaic, which is incomprehensible why it differs from the canonical Christian Prayer by 9/10.

The long-term effect of Prayer on EEG, HRV and GDV will be the subject of a separate article, and in this one we focus on immediate neurotropic effects.

So, the first pattern reflects the inhibitory effect of Prayer on elevated and upper limit levels of SPD of $\boldsymbol{\theta}$-and $\boldsymbol{\delta}$-rhythm in frontal loci (Fig. 2).

The second pattern (Fig. 3) reflects a decrease in normal SPD levels of $\boldsymbol{\beta}$-rhythm as well as $\boldsymbol{\theta}$-rhythm in the frontal, central, temporal and parietal loci. In addition, $\boldsymbol{\beta}$-rhythm variability and $\boldsymbol{\delta}$-rhythm asymmetry decrease, and the initial slight left-side lateralization of $\boldsymbol{\beta}$-and $\boldsymbol{\theta}$-rhythms further drifts to the left.
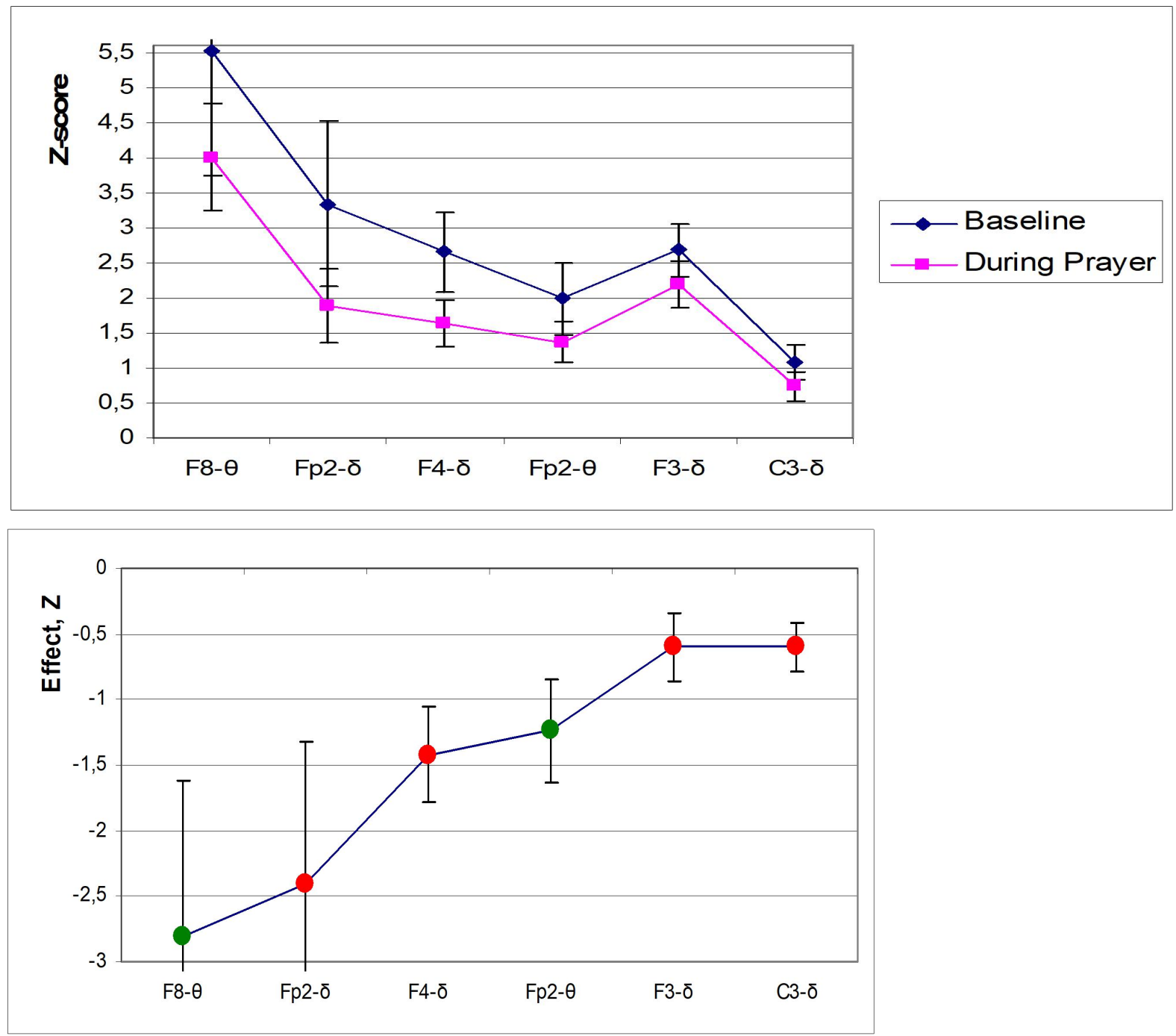
Fig. 2. Inhibitory immediate effect of Prayer on elevated and upper limit EEG parameters
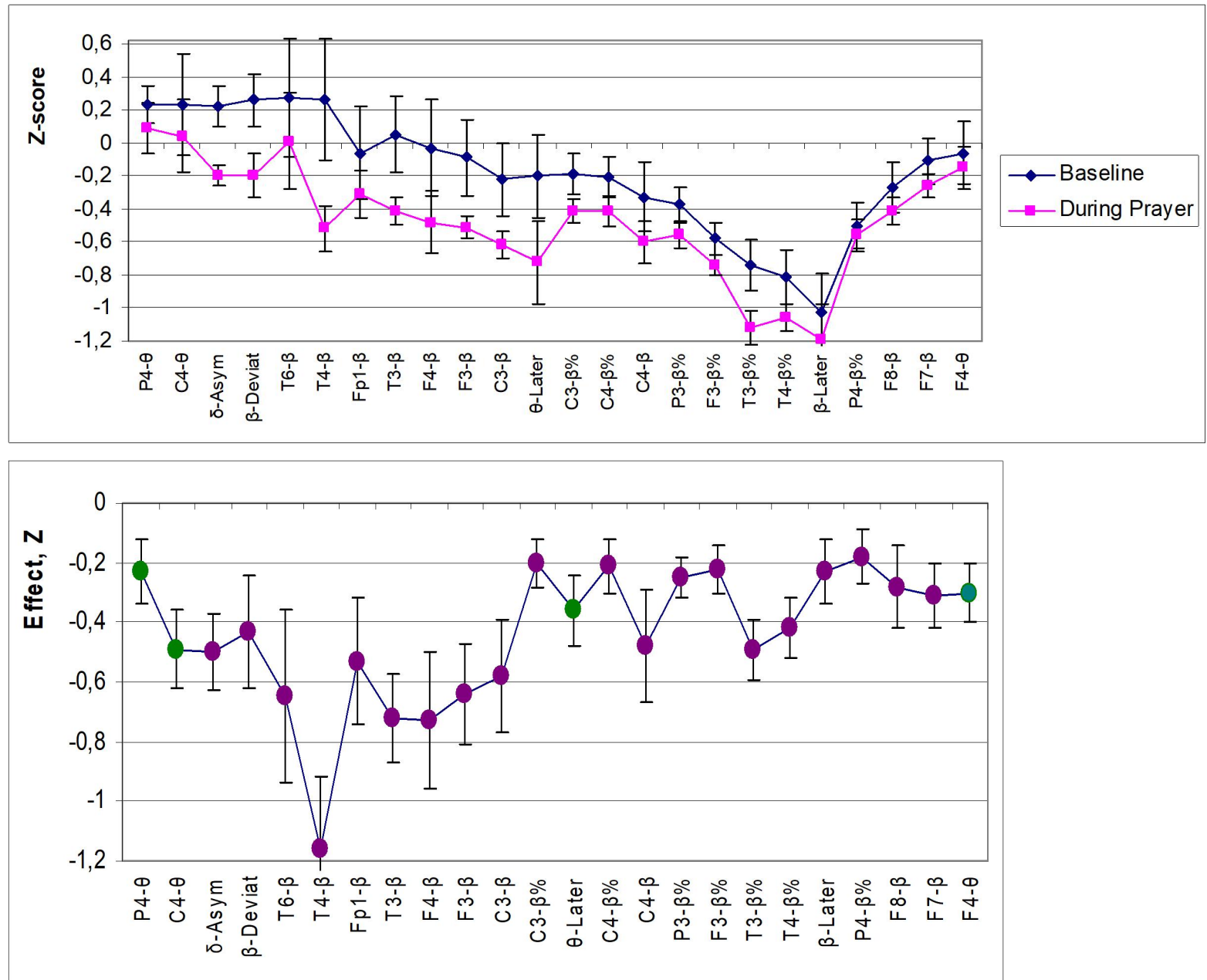

Fig. 3. Inhibitory immediate effect of Prayer on normal EEG parameters

The activating neurotropic effect of Prayer is reflected in three patterns. The first pattern (Fig. 4) reflects a small but significant increase in initially normal levels of $\boldsymbol{\beta}$-rhythm index and asymmetry and SPD entropy in locus C3, as well as a further increase in elevated $\boldsymbol{\delta}$ rhythm SPD levels in loci P3 and T3. 

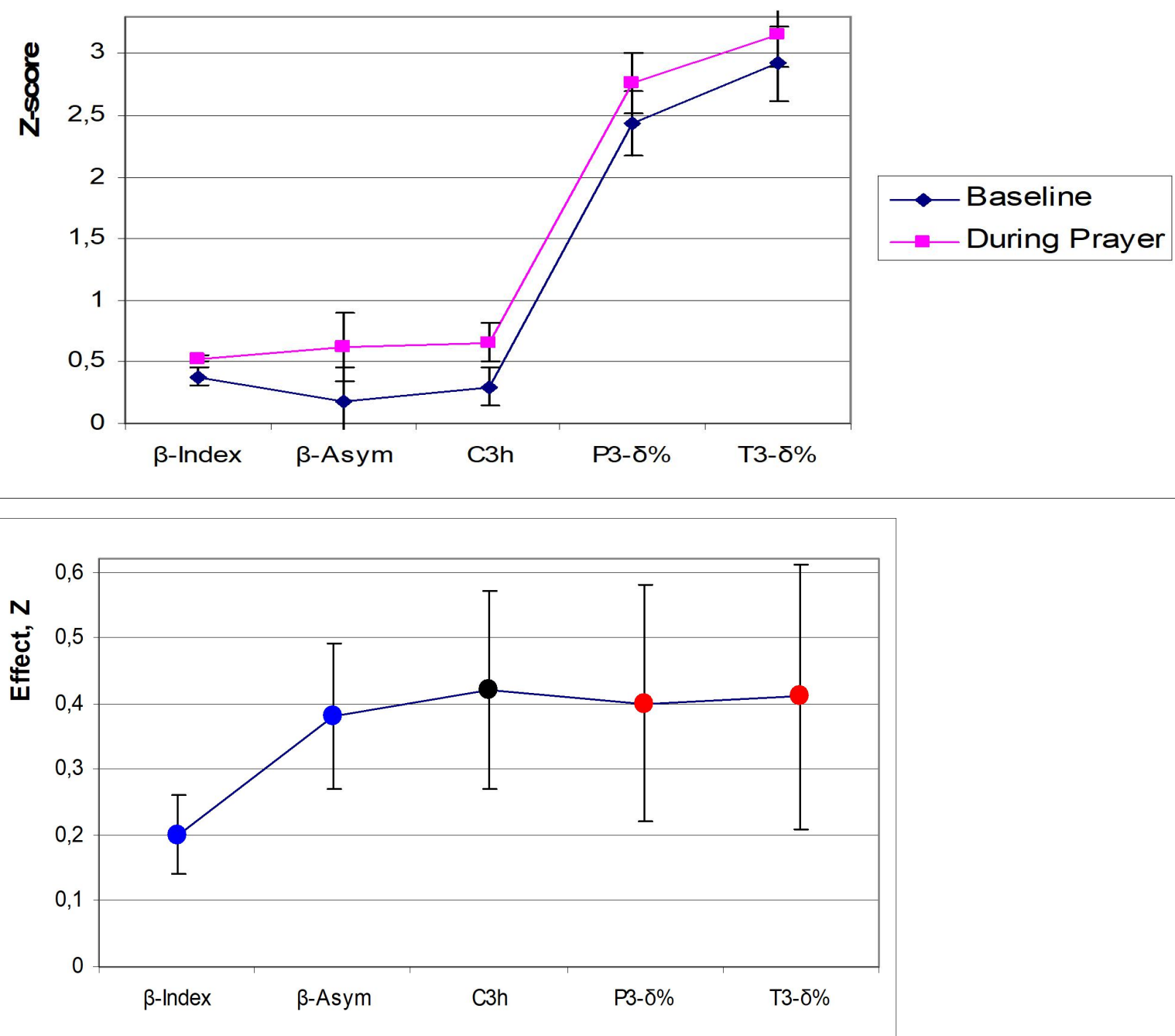

Fig. 4. Enhancing immediate effect of Prayer on normal and elevated EEG parameters

The second pattern (Fig. 5) reflects the same slight increase in normal SPD levels of $\boldsymbol{\theta}$ rhythm in loci T3, T5, T6, O2 and $\boldsymbol{\alpha}$-rhythm in locus T5, as well as their indices and entropy SPD in locus $\mathrm{O} 2$.

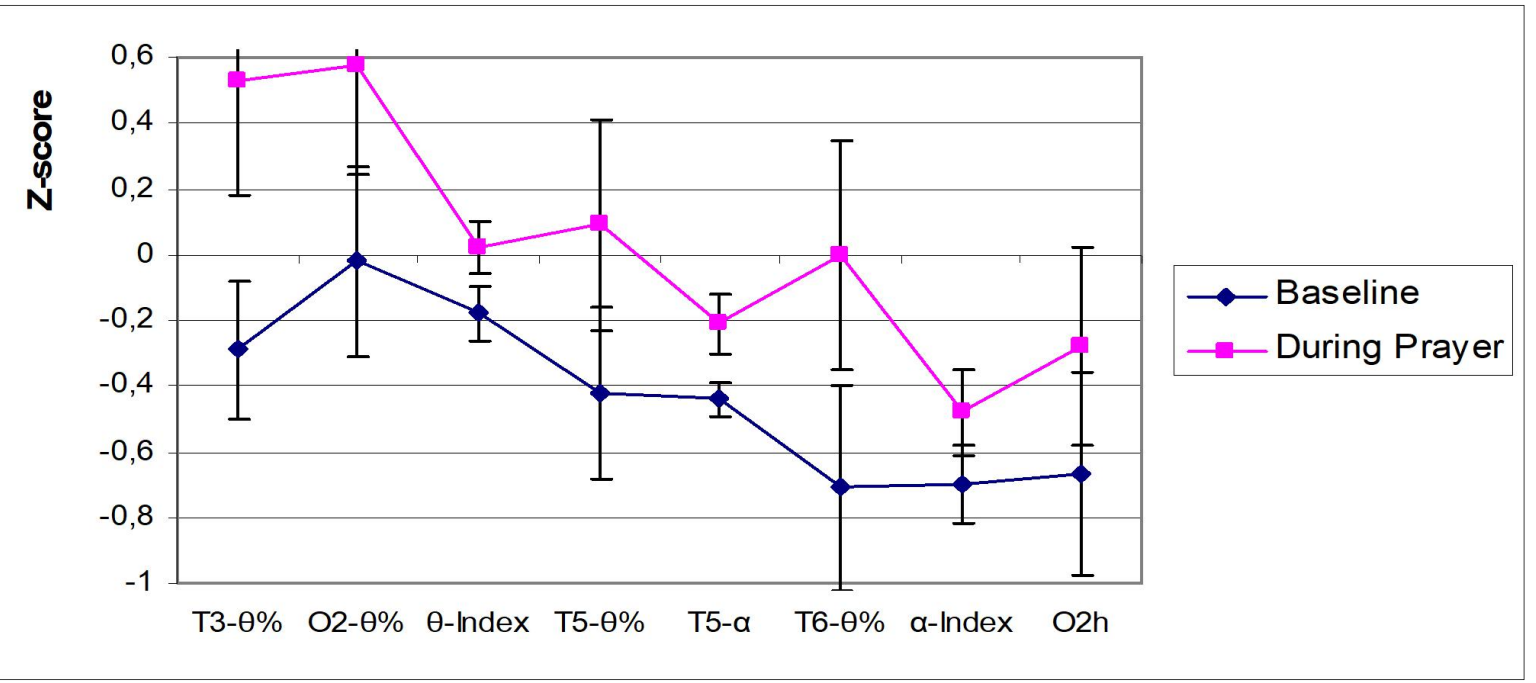




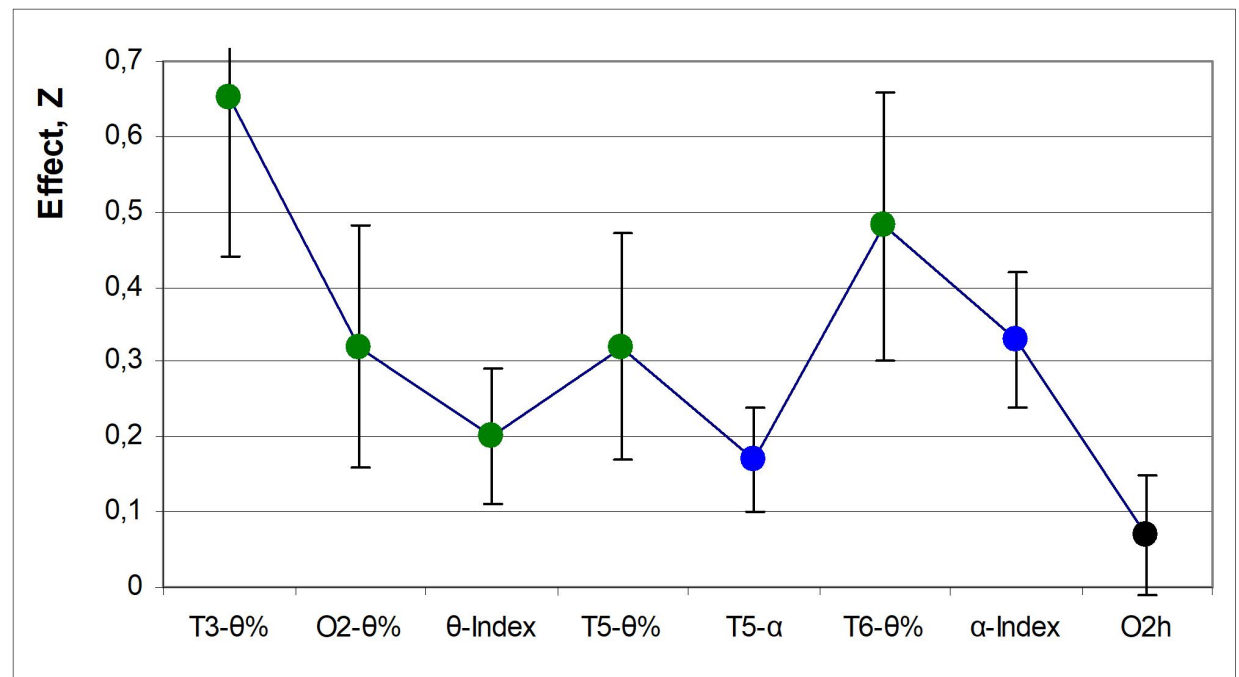

Fig. 5. Enhancing immediate effect of Prayer on normal and lower border EEG parameters

The third pattern (Fig. 6) reflects a slight increase in amplitude and SPD of $\boldsymbol{\alpha}$-rhythm in central, frontal, temporal and occipital loci.
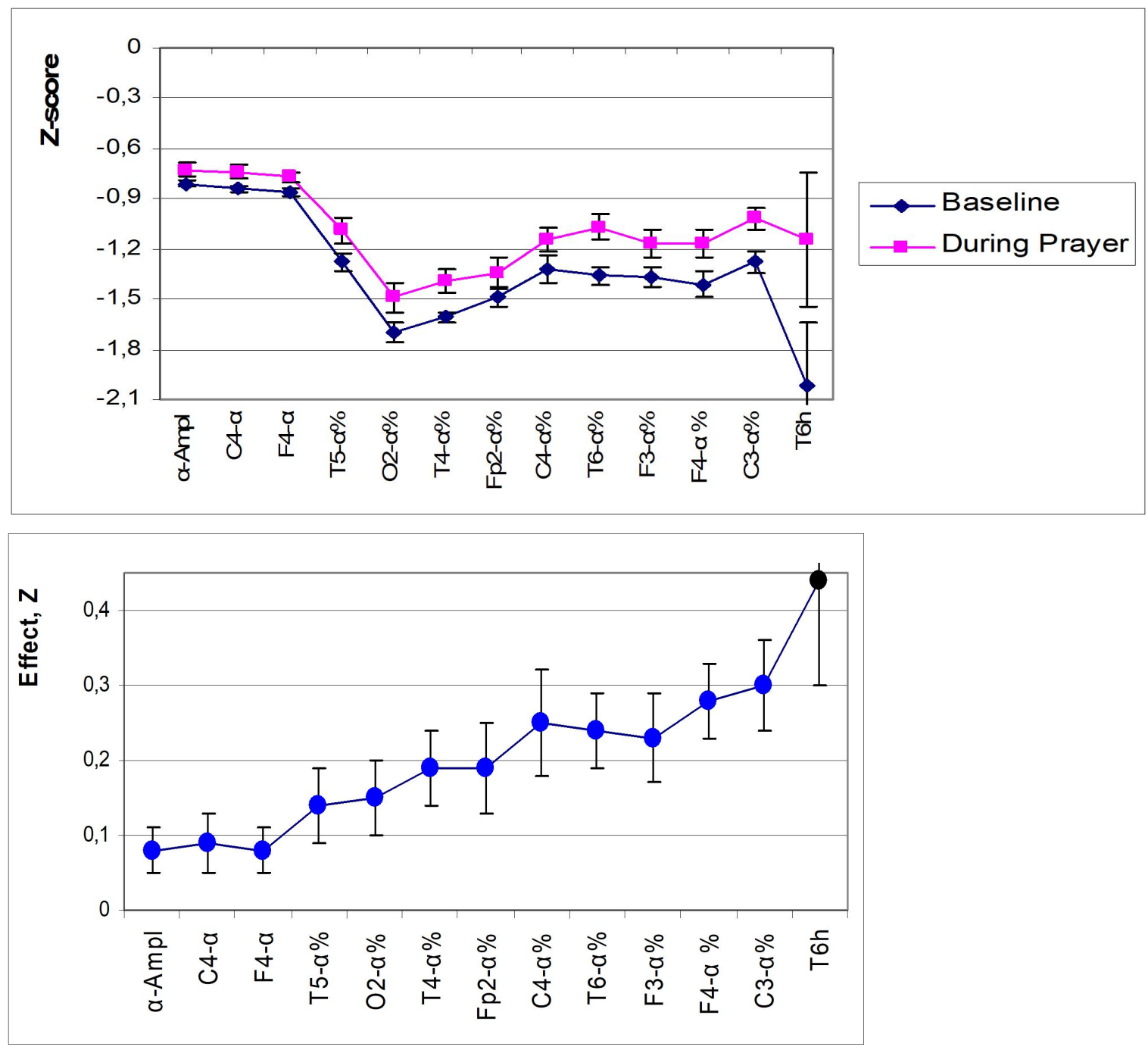
Fig. 6. Enhancing immediate effect of Prayer on normal and lower border EEG parameters

Tables 3 and 4 contains HRV parameters whose changes are statistically significant $(p \leq 0,05)$ as well as those which appeared in the structure of the discriminant model. Pseudocoloring is used to distinguish sympathetic and vagal markers as well as entropy.

Table 3. HRV Variables, their Means and Changes caused by Prayer. Parameters are ranked by direct differences of $\mathrm{Z}$-score (see following table)

\begin{tabular}{|c|c|c|c|c|}
\hline \multirow[t]{2}{*}{ Variables } & \multirow{2}{*}{$\begin{array}{c}\text { Reference } \\
\text { level } \\
(88)\end{array}$} & \multicolumn{2}{|c|}{ Mean \pm SE } & \multirow{2}{*}{$\begin{array}{c}\text { Difference, } \\
\text { Mean } \pm \text { SE } \\
(7)\end{array}$} \\
\hline & & $\begin{array}{l}\text { Baseline } \\
\text { (7) }\end{array}$ & $\begin{array}{l}\text { Prayer } \\
\text { (7) }\end{array}$ & \\
\hline$(\mathrm{VLF}+\mathrm{LF}) / \mathrm{HF}$ & $7,4 \pm 0,4$ & $6,0 \pm 1,1$ & $8,4 \pm 1,4$ & $+2,4 \pm 0,6$ \\
\hline $\mathrm{LF} / \mathrm{HF}$ & $2,94 \pm 0,23$ & $2,37 \pm 0,84$ & $3,60 \pm 1,65$ & $+1,23 \pm 0,57$ \\
\hline LFnu HRV SPD, \% & $65,0 \pm 1,5$ & $60,9 \pm 7,4$ & $67,2 \pm 6,3$ & $+6,2 \pm 1,4$ \\
\hline TINN HRV, units & $11,2 \pm 0,3$ & $8,7 \pm 0,8$ & $9,5 \pm 1,1$ & $+0,8 \pm 0,2$ \\
\hline VLF HRV SPD, \% & $53,4 \pm 2,2$ & $47,5 \pm 5,2$ & $54,1 \pm 7,7$ & $+6,6 \pm 2,6$ \\
\hline LF HRV SPD, \% & $27,1 \pm 1,2$ & $27,8 \pm 7,1$ & $31,1 \pm 8,9$ & $+3,3 \pm 1,7$ \\
\hline AMo HRV, \% & $39,2 \pm 1,2$ & $51,0 \pm 3,4$ & $49,2 \pm 3,4$ & $-1,8 \pm 1,0$ \\
\hline Moda HRV, msec & $800 \pm 11$ & $940 \pm 62$ & $920 \pm 76$ & $-20 \pm 14$ \\
\hline SDNN HRV, msec & $54 \pm 3$ & $47 \pm 11$ & $41 \pm 7$ & $-6,1 \pm 3,6$ \\
\hline HF HRV SPD, \% & $15,2 \pm 1,4$ & $15,4 \pm 2,9$ & $11,5 \pm 1,5$ & $-3,9 \pm 1,1$ \\
\hline HF HRV SPD, msec ${ }^{2}$ & $286 \pm 23$ & $325 \pm 139$ & $198 \pm 53$ & $-127 \pm 59$ \\
\hline Entropy SPD HRV & $0,79 \pm 0,01$ & $0,80 \pm 0,03$ & $0,67 \pm 0,04$ & $-0,12 \pm 0,02$ \\
\hline ULF HRV SPD, \% & $4,3 \pm 0,4$ & $9,3 \pm 3,6$ & $3,3 \pm 1,3$ & $-6,0 \pm 2,6$ \\
\hline ULF SPD, In msec ${ }^{2}$ & $4,80 \pm 0,50$ & $4,68 \pm 0,59$ & $3,53 \pm 0,31$ & $-1,16 \pm 0,45$ \\
\hline
\end{tabular}

Table 4. Z-scores of HRV Variables and their Changes caused by Prayer

\begin{tabular}{|l|c|l|l|l|}
\hline \multirow{2}{*}{ Variables } & \multirow{2}{*}{$\begin{array}{l}\text { Variability } \\
\text { coefficients }\end{array}$} & $\begin{array}{l}\text { Baseline } \\
(7)\end{array}$ & $\begin{array}{l}\text { Prayer } \\
(7)\end{array}$ & $\begin{array}{c}\text { Difference, } \\
\text { Z } \pm \text { SE } \\
(7)\end{array}$ \\
\hline (VLF+LF)/HF & 0,563 & $-0,28 \pm 0,32$ & $+0,42 \pm 0,51$ & $+0,69 \pm 0,18$ \\
\hline LF/HF & 0,733 & $-0,24 \pm 0,42$ & $+0,36 \pm 0,83$ & $+0,61 \pm 0,28$ \\
\hline LFnu HRV SPD, \% & 0,210 & $-0,28 \pm 0,57$ & $+0,18 \pm 0,51$ & $+0,46 \pm 0,10$ \\
\hline TIN HRV, units & 0,217 & $-1,03 \pm 0,31$ & $-0,69 \pm 0,43$ & $+0,34 \pm 0,09$ \\
\hline VLF HRV SPD, \% & 0,378 & $-0,29 \pm 0,26$ & $+0,03 \pm 0,38$ & $+0,33 \pm 0,13$ \\
\hline LF HRV SPD, \% & 0,414 & $+0,06 \pm 0,63$ & $+0,36 \pm 0,79$ & $+\mathbf{0 , 2 9} \pm \mathbf{0 , 1 5}$ \\
\hline AMo HRV, \% & 0,392 & $+0,78 \pm 0,24$ & $+0,64 \pm 0,24$ & $\mathbf{- 0 , 1 4 \pm 0 , 0 8}$ \\
\hline Moda HRV, msec & 0,114 & $+0,60 \pm 0,60$ & $+0,40 \pm 0,75$ & $\mathbf{- 0 , 2 0 \pm 0 , 1 4}$ \\
\hline SDNN HRV, msec & 0,588 & $-0,07 \pm 0,42$ & $-0,31 \pm 0,24$ & $\mathbf{- 0 , 2 4 \pm 0 , 1 4}$ \\
\hline HF HRV SPD, \% & 0,861 & $+0,02 \pm 0,22$ & $-0,28 \pm 0,11$ & $-0,30 \pm 0,08$ \\
\hline HF HRV SPD, msec ${ }^{2}$ & 0,763 & $0,00 \pm 0,35$ & $-0,43 \pm 0,14$ & $-0,43 \pm 0,17$ \\
\hline Entropy SPD HRV & 0,127 & $+0,09 \pm 0,31$ & $-1,15 \pm 0,40$ & $-1,24 \pm 0,20$ \\
\hline ULF HRV SPD, \% & 0,926 & $1,26 \pm 0,90$ & $-0,24 \pm 0,32$ & $-1,50 \pm 0,64$ \\
\hline ULF HRV SPD, msec ${ }^{2}$ & 1,001 & $-0,12 \pm 0,59$ & $-1,27 \pm 0,31$ & $-1,16 \pm 0,45$ \\
\hline
\end{tabular}



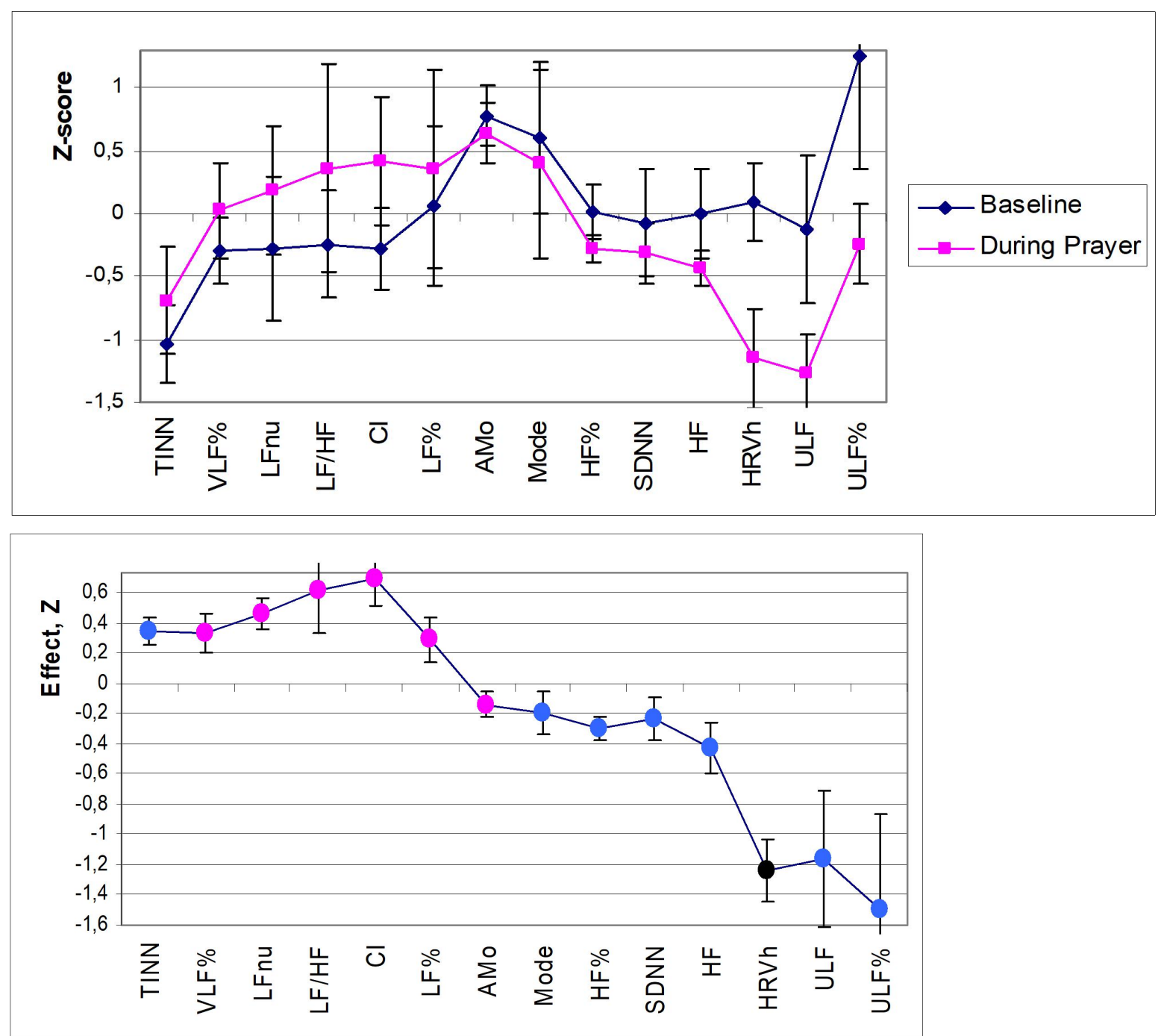

Fig. 7. Modulating immediate effect of Prayer on HRV parameters

LFnu is admitted HRV markers of Sympathetic tone [1,3]. It is speculated that absolute SPD LF band reflects mainly Sympathetic outflow or both Sympathetic and Vagal origin [2]; VLF band $(0,04 \div 0,015 \mathrm{~Hz})$ associated with oscillation blood levels of rennin-angiotensin $(0,04 \mathrm{~Hz})$ and epinephrine $(0,025 \mathrm{~Hz})$, reflects thermoregulatory cycles [cit by: 2,7$]$, cerebral ergotropic and metabolotropic outflows [cit by: 1], activation of cerebral sympatho-adrenal system [cyt by: 4], sympathetic activity [cit by: 6]; ULF band $(0,015 \div 0,003 \mathrm{~Hz})$ associated with oscillation blood level of norepinephrine $(0,002 \mathrm{~Hz})$ as well as $17-\mathrm{OCS}(0,0019 \mathrm{~Hz})$ [cit by: 7].

upregulation activating influence of Parasympathetic nucleus of Brain Stem (probably nucleus ambiguous) as well as downregulation of inhibiting influence of Sympathetic nucleus of Brain Stem (probably caudal and rostral ventro-lateral medulla). On the other hand, generating $\alpha$-Rhythm neural structures realizes downregulation IgM by inhibition activating Parasympathetic nucleus.

the absolute values of the VLF band correlate significantly with the markers of the vagus tone directly, and with the markers of sympathetic tone inversely. This gives us reason to believe that VLF (as well as LF) bands are vagus markers. Instead, the relative VLF band values are 
associated with vagus and sympathetic markers in the opposite way, that is, a sympathetic marker, as is commonly recognized for LFnu.

Unfortunately, our device does not have the option "Tomography", so we can only assume that loci $\mathrm{C} 3$ and $\mathrm{C} 4$ projected hippocampus, and loci T3 and T4 reflect the activity of the amygdala [17]. It is more likely that the frontal loci record the activity of anterior cingulate [3] as well as orbito-frontal cortex. It is shown that the cortical thickness of an area within these regions is positively correlated with two HRV markers of parasympathetic activity both HF [7,25] and RMSSD [26].

YY Tang et al. [20] analysed the correlation between the changes in frontal midline $\theta$ power (related to generators in the anterior cingulate cortex [3]) and HFnu HRV. After 5 days of integrative body-mind training correlations between $\mathrm{HFnu}$ and $\mathrm{Fz}-\theta, \mathrm{FCz}-\theta$ as well as $\mathrm{Cz}-\theta$ were significantly positive. Previously we [15] also found correlations between HFnu and F4$\theta$ and P4- $\theta$, between HF\% and Fp1- $\theta$ and P4- $\theta$ also between RMSSD and P4- $\theta$.

GE Prinsloo et al. [16] found that less pronounced changes in HRV, due to work-related stress, accompanied by higher relative SPD Fz- $\theta, \operatorname{Pz}-\theta$ and $\mathrm{Cz}-\theta$, lower fronto-central relative $\beta$ power and higher $\theta / \beta$ ratio. It is also perfectly consistent with our [15] data on a negative correlation LFnu, LF\% and LF/HF with F4- $\theta, \mathrm{P} 4-\theta, \mathrm{F} 7-\theta, \mathrm{F} 8-\theta$ and positive correlation with F7- $\beta$ and F8- $\beta$ - on the one hand, and a positive correlation HF\% with Fp1- $\theta$ and P4- $\theta$ and negative with $\mathrm{P} 4-\beta$ - on the other side.

As the discussion on the neural correlates of LF, VLF and ULF bands of HRV continues, we consider it appropriate to provide our own data on their relationship. We found that the commonly recognized vagus markers $\mathrm{HF}$ and RMSSD, closely correlating with each other $(\mathrm{r}=0,93)$ and moderately negative with the sympathetic markers LFnu $(-0,47$ and $-0,55)$ as well as LF/HF $(-0,35$ and $-0,44)$, correlate positively strongly with LF $(0,83$ and 0,77$)$ and medially with $\operatorname{VLF}(0,44$ and 0,57$)$ as well as $\operatorname{ULF}(0,47$ and 0,45$)$, then there are no correlation of these HRV bands with sympathetic markers $(r=-0.18 \div-0.08)$. Therefore, in our study, the LF band reflects the vagal tone definitely, which was maximal in individuals with normal entropy.

Table 5. Discriminant Function Analysis Summary and Summary of Stepwise Analysis. Змінні ранжовані за критерісм $\Lambda$

Step 17, $\mathrm{N}$ of variables in model: 17 ; Grouping: 2 groups

Canonical R=0,919; Wilks' Lambda=0,155; approx. $\mathrm{F}_{(17)}=14,7 ; \chi_{(17)}^{2}=99,6 ; \mathrm{p}<10^{-6}$

\begin{tabular}{|c|c|c|c|c|c|c|c|c|c|c|}
\hline $\begin{array}{l}\text { Variables currently } \\
\text { in the mode }\end{array}$ & $\begin{array}{l}\text { Wilks } \\
\Lambda\end{array}$ & $\begin{array}{l}\text { Parti- } \\
\text { al } \Lambda\end{array}$ & $\begin{array}{l}\text { F-re- } \\
\text { move }\end{array}$ & $\begin{array}{l}\text { p-le- } \\
\text { vel }\end{array}$ & $\begin{array}{l}\text { Tole- } \\
\text { rancy }\end{array}$ & $\begin{array}{l}\mathrm{F} \text { to } \\
\text { enter }\end{array}$ & $\begin{array}{l}\text { p-le- } \\
\text { vel }\end{array}$ & $\Lambda$ & $\begin{array}{l}\text { F-va- } \\
\text { lue }\end{array}$ & $\begin{array}{l}\text { p-le- } \\
\text { vel }\end{array}$ \\
\hline Entropy SPD HRV & ,183 & 847 & 8,3 & 006 & 001 & 13,9 & $10^{-3}$ &, 816 & 13,9 & $10^{-3}$ \\
\hline LFnu HRV SPD, \% & ,238 & ,652 & 24,6 & $10^{-5}$ &, 034 & 14,3 & $10^{-3}$ & ,661 & 15,6 & $10^{-5}$ \\
\hline F3- $\alpha$ SPD, \% & 167 & 931 & 3,4 & 070 & 397 & 6,0 & 017 &, 601 & 13,3 & $10^{-6}$ \\
\hline$\theta$-rhythm Index, \% &, 173 & 897 & 5,3 &, 026 &, 432 & 4,2 &, 044 &, 561 & 11,6 & $10^{-6}$ \\
\hline$\delta$-rhythm Asymm., \% & , 185 & 842 & 8,6 &, 005 & ,313 & 4,8 &, 032 & ,517 & 10,8 & $10^{-6}$ \\
\hline ULF HRV SPD, \% & 204 &, 760 & 14,5 & $10^{-3}$ & 003 & 5,5 & 022 & 472 & 10,6 & $10^{-6}$ \\
\hline Entropy SPD O2 &, 161 & 962 & 1,8 &, 186 &, 074 & 2,2 &, 140 & ,454 & 9,6 & $10^{-6}$ \\
\hline T4- $\alpha$ SPD, \% & 157 & ,990 & 0,5 & ,489 & ,181 & 7,2 & ,009 & ,401 & 10,3 & $10^{-6}$ \\
\hline T3- $\theta$ SPD, \% & 163 & ,952 & 2,3 & ,134 & ,142 & 3,8 &, 056 &, 375 & 10,0 & $10^{-6}$ \\
\hline HF HRV SPD, \% &, 185 &, 838 & 8,9 & 005 & 031 & 1,5 & 229 &, 364 & 9,2 & $10^{-6}$ \\
\hline AMo HRV, \% & 255 & ,609 & 29,6 & $10^{-5}$ &, 007 & 1,6 & ,211 &, 353 & 8,6 & $10^{-6}$ \\
\hline SDNN HRV, msec & ,324 & ,479 & 50,0 & $10^{-6}$ &, 002 & 6,4 &, 015 & ,314 & 9,3 & $10^{-6}$ \\
\hline HF HRV SPD, msec ${ }^{2}$ & 230 & 674 & 22,2 & $10^{-4}$ & 003 & 17,6 & $10^{-4}$ & 232 & 12,7 & $10^{-6}$ \\
\hline $\mathrm{ULF}_{\mathrm{URV}} \mathrm{SPD}, \mathrm{msec}^{2}$ & 213 &, 730 & 17,0 & $10^{-4}$ &, 008 & 11,7 & 001 &, 188 & 15,1 & $10^{-6}$ \\
\hline T6- $\beta$ SPD, $\mu V^{2} / H z$ &, 163 & 956 & 2,1 &, 150 & 098 & 5,2 & 027 &, 169 & 15,7 & $10^{-6}$ \\
\hline
\end{tabular}




\begin{tabular}{|l|l|l|l|l|l|l|l|l|l|l|}
\hline$($ VLF+LF $/$ HF &, 166 &, 934 & 3,2 &, 078 &, 004 & 2,0 &, 166 &, 163 & 15,1 & $10^{-6}$ \\
\hline Moda HRV, msec &, 163 &, 956 & 2,1 &, 151 &, 021 & 2,1 &, 151 &, 155 & 14,7 & $10^{-6}$ \\
\hline
\end{tabular}

Table 6. Means discriminant Variables before and durig Prayer and their direct differences. Змінні ранжовані за вираженістю змін

\begin{tabular}{|c|c|c|c|}
\hline \multirow[b]{2}{*}{$\begin{array}{l}\text { Variables currently } \\
\text { in the mode }\end{array}$} & \multicolumn{2}{|c|}{$\mathrm{Z}$ score $\pm \mathrm{SE}$} & \multirow{2}{*}{$\begin{array}{c}\text { Direct } \\
\text { differences } \\
\mathrm{Z} \pm \mathrm{SE}\end{array}$} \\
\hline & $\begin{array}{l}\text { Before } \\
\text { Prayer }\end{array}$ & $\begin{array}{l}\text { During } \\
\text { Prayer }\end{array}$ & \\
\hline Entropy SPD HRV & $+0,09 \pm 0,31$ & $-1,15 \pm 0,40$ & $-1,24 \pm 0,20$ \\
\hline ULF HRV SPD, \% & $1,26 \pm 0,90$ & $-0,24 \pm 0,32$ & $-1,50 \pm 0,64$ \\
\hline$\delta$-rhythm Asymmetry, \% & $+0,22 \pm 0,12$ & $-0,20 \pm 0,06$ & $-0,50 \pm 0,13$ \\
\hline ULF HRV SPD, msec ${ }^{2}$ & $-0,12 \pm 0,59$ & $-1,27 \pm 0,31$ & $-1,16 \pm 0,45$ \\
\hline HF HRV SPD, \% & $+0,02 \pm 0,22$ & $-0,28 \pm 0,11$ & $-0,30 \pm 0,08$ \\
\hline AMo HRV, \% & $+0,78 \pm 0,24$ & $+0,64 \pm 0,24$ & $-0,14 \pm 0,08$ \\
\hline Moda HRV, msec & $+0,60 \pm 0,60$ & $+0,40 \pm 0,75$ & $-0,20 \pm 0,14$ \\
\hline HF HRV SPD, msec ${ }^{2}$ & $0,00 \pm 0,35$ & $-0,43 \pm 0,14$ & $-0,43 \pm 0,17$ \\
\hline T6- $\beta$ SPD,$\mu V^{2} / H z$ & $+0,27 \pm 0,36$ & $+0,01 \pm 0,29$ & $-0,65 \pm 0,29$ \\
\hline SDNN HRV, msec & $-0,07 \pm 0,42$ & $-0,31 \pm 0,24$ & $-0,24 \pm 0,14$ \\
\hline$(\mathrm{VLF}+\mathrm{LF}) / \mathrm{HF}$ & $-0,28 \pm 0,32$ & $+0,42 \pm 0,51$ & $+0,69 \pm 0,18$ \\
\hline T4-a SPD, \% & $-1,61 \pm 0,03$ & $-1,39 \pm 0,07$ & $+0,19 \pm 0,05$ \\
\hline T3- $\theta$ SPD, $\%$ & $-0,29 \pm 0,21$ & $+0,53 \pm 0,35$ & $+0,65 \pm 0,21$ \\
\hline F3- $\alpha$ SPD, $\%$ & $-1,37 \pm 0,06$ & $-1,17 \pm 0,08$ & $+0,23 \pm 0,06$ \\
\hline LFnu HRV SPD, \% & $-0,28 \pm 0,57$ & $+0,18 \pm 0,51$ & $+0,46 \pm 0,10$ \\
\hline$\theta$-rhythm Index, $\%$ & $-0,18 \pm 0,08$ & $+0,02 \pm 0,08$ & $+0,20 \pm 0,09$ \\
\hline Entropy SPD in locus $\mathrm{O2}$ & $-0,67 \pm 0,31$ & $-0,28 \pm 0,30$ & $+0,07 \pm 0,08$ \\
\hline
\end{tabular}

Table 7. Standardized, Raw and Structural Coefficients for Canonical Variables, their Means and Changes caused by Prayer

\begin{tabular}{|c|c|c|c|}
\hline \multirow{2}{*}{$\begin{array}{l}\text { Variables currently } \\
\text { in the mode }\end{array}$} & \multicolumn{3}{|c|}{ Coefficients } \\
\hline & Standardized & Raw & Structural \\
\hline Entropy SPD HRV & $-11,09$ & $-74,06$ &,- 203 \\
\hline ULF HRV SPD, $\%$ & 10,29 & 1,595 &,- 202 \\
\hline$\delta$-rhythm Asymmetry, $\%$ &,- 773 &,- 053 &,- 165 \\
\hline ULF HRV SPD, msec $^{2}$ & $-6,386$ &,- 009 &,- 138 \\
\hline HF HRV SPD, $\%$ & $-2,472$ &,- 364 &,- 096 \\
\hline AMo HRV, \% & $-8,019$ &,- 914 &,- 082 \\
\hline Moda HRV, msec & $-1,575$ &,- 009 &,- 082 \\
\hline HF HRV SPD, $\mathrm{msec}^{2}$ & 10,77 &, 042 &,- 079 \\
\hline T6- $\beta$ SPD, $\mu V^{2} / \mathrm{Hz}$ &, 735 &, 005 &,- 031 \\
\hline SDNN HRV, msec & $-18,93$ &,- 840 &,- 026 \\
\hline$(\mathrm{VLF}+\mathrm{LF}) / \mathrm{HF}$ & $-4,256$ & $-1,196$ & ,159 \\
\hline T4- $\alpha$ SPD, $\%$ & ,261 &, 040 & ,137 \\
\hline T3- $\theta$ SPD, $\%$ & ,633 &, 107 & ,098 \\
\hline F3- $\alpha$ SPD, \% &, 455 &, 0518 &, 096 \\
\hline LFnu HRV SPD, \% & $-3,473$ &,- 193 & ,089 \\
\hline$\theta$-rhythm Index, \% &, 532 &, 0246 & 085 \\
\hline Entropy SPD in locus $\mathrm{O} 2$ &,- 775 & $-2,487$ & ,049 \\
\hline $\mathrm{D}_{\mathrm{M}}{ }^{2}=22,1 ; \mathrm{F}=14,7 ; \mathrm{p}<10^{-6}$ & Constant & 149,8 & \\
\hline
\end{tabular}




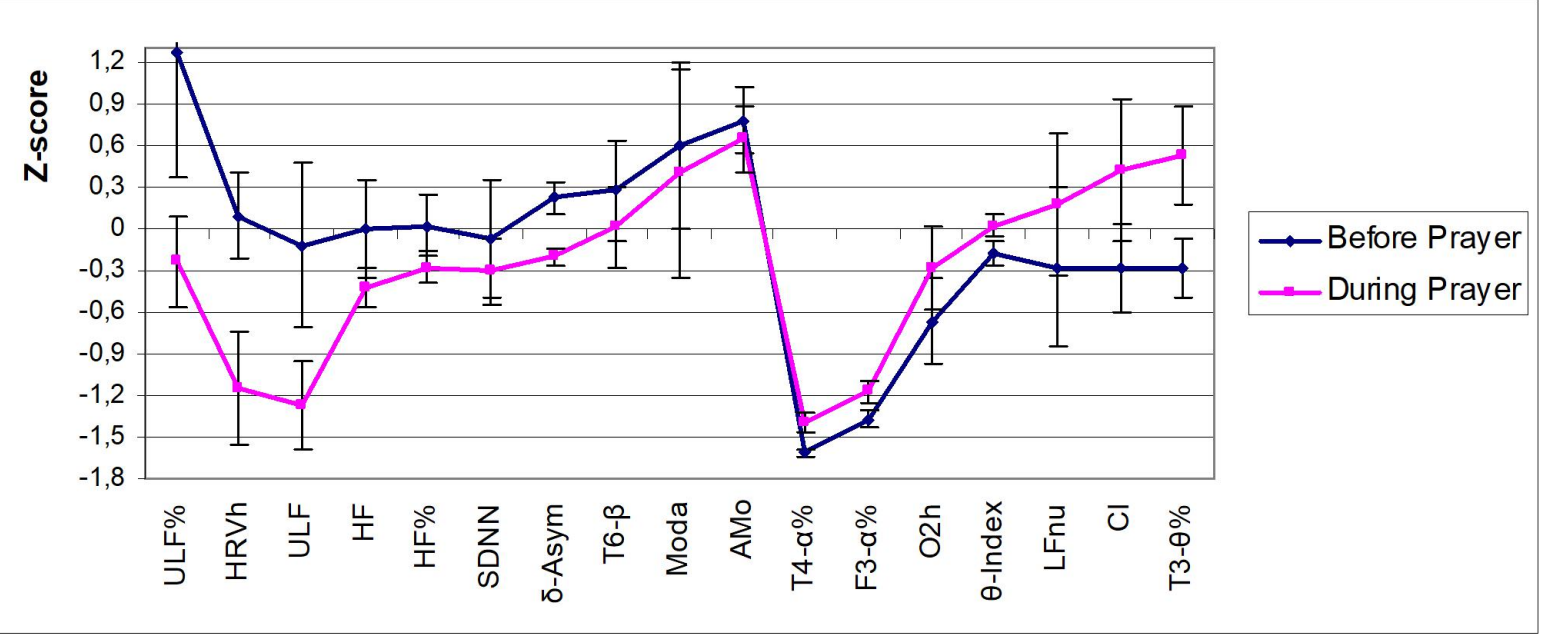

Fig. 8. Profiles of discriminant EEG\&HRV parameters (Mean \pm SE) before and during Prayer

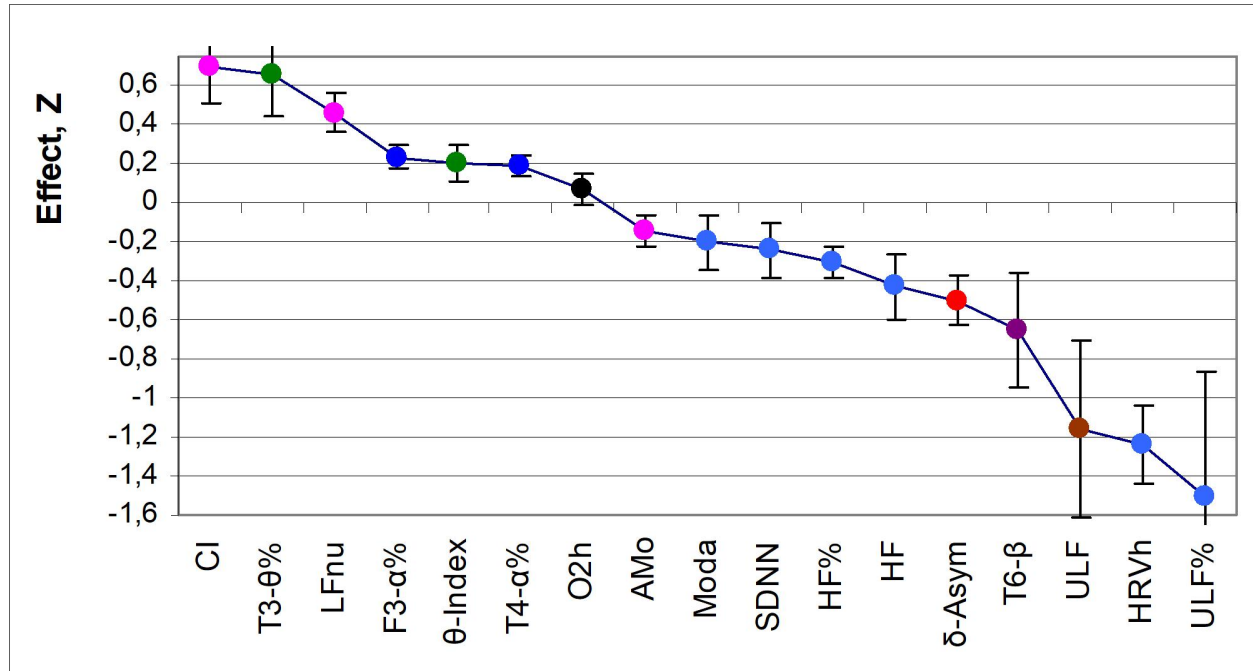

Fig. 9. Profile of charecreristic effects (Mean \pm SE) of Prayer on EEG\&HRV parameters

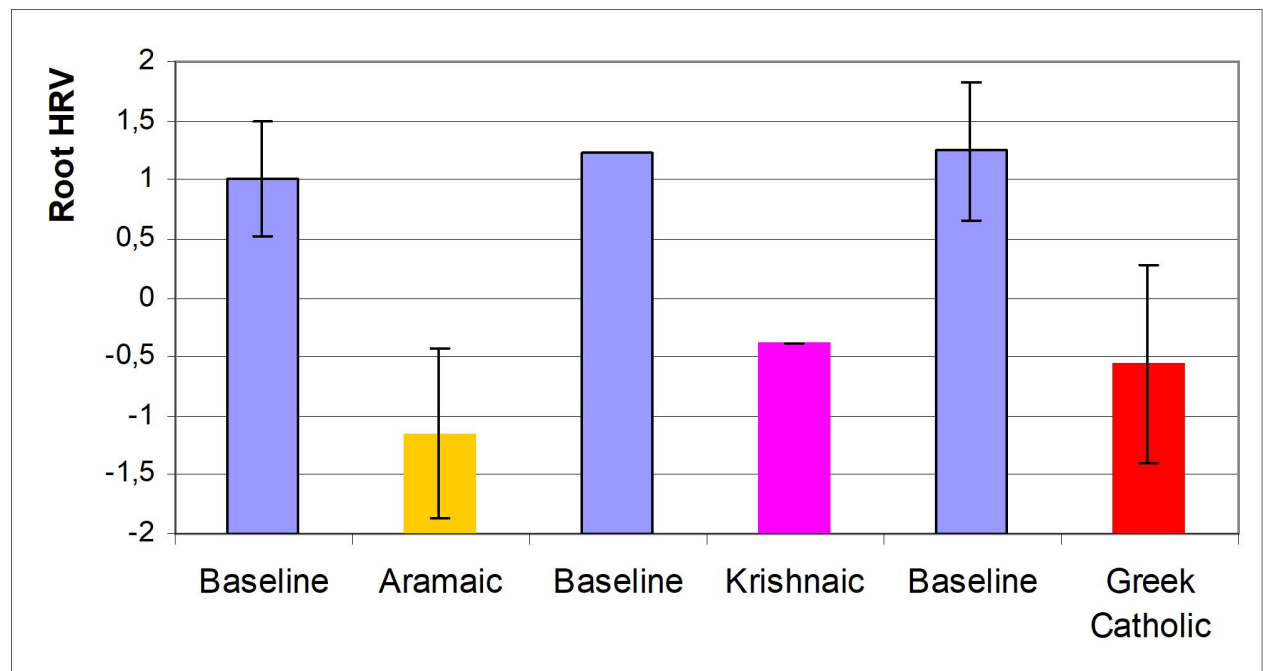



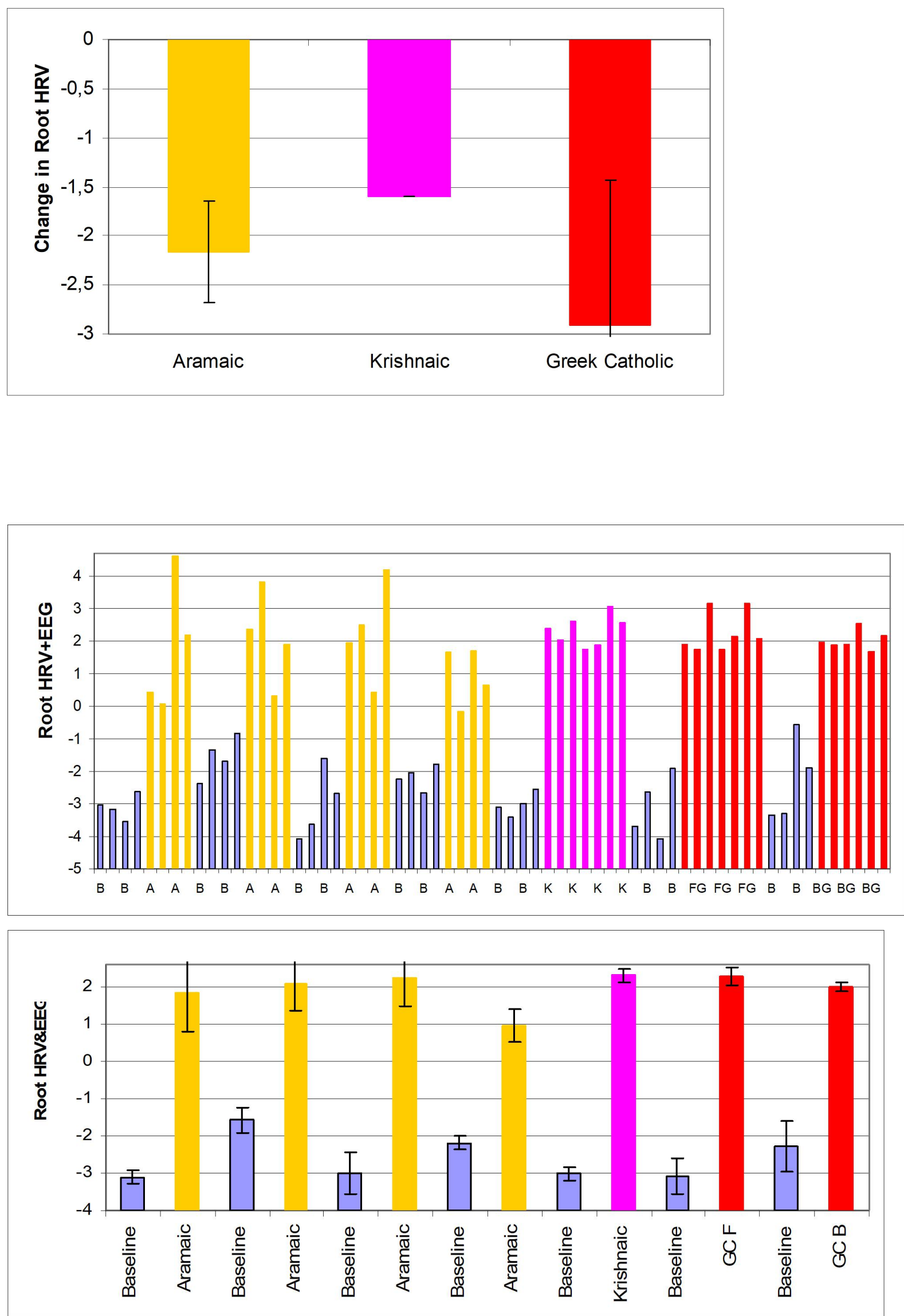

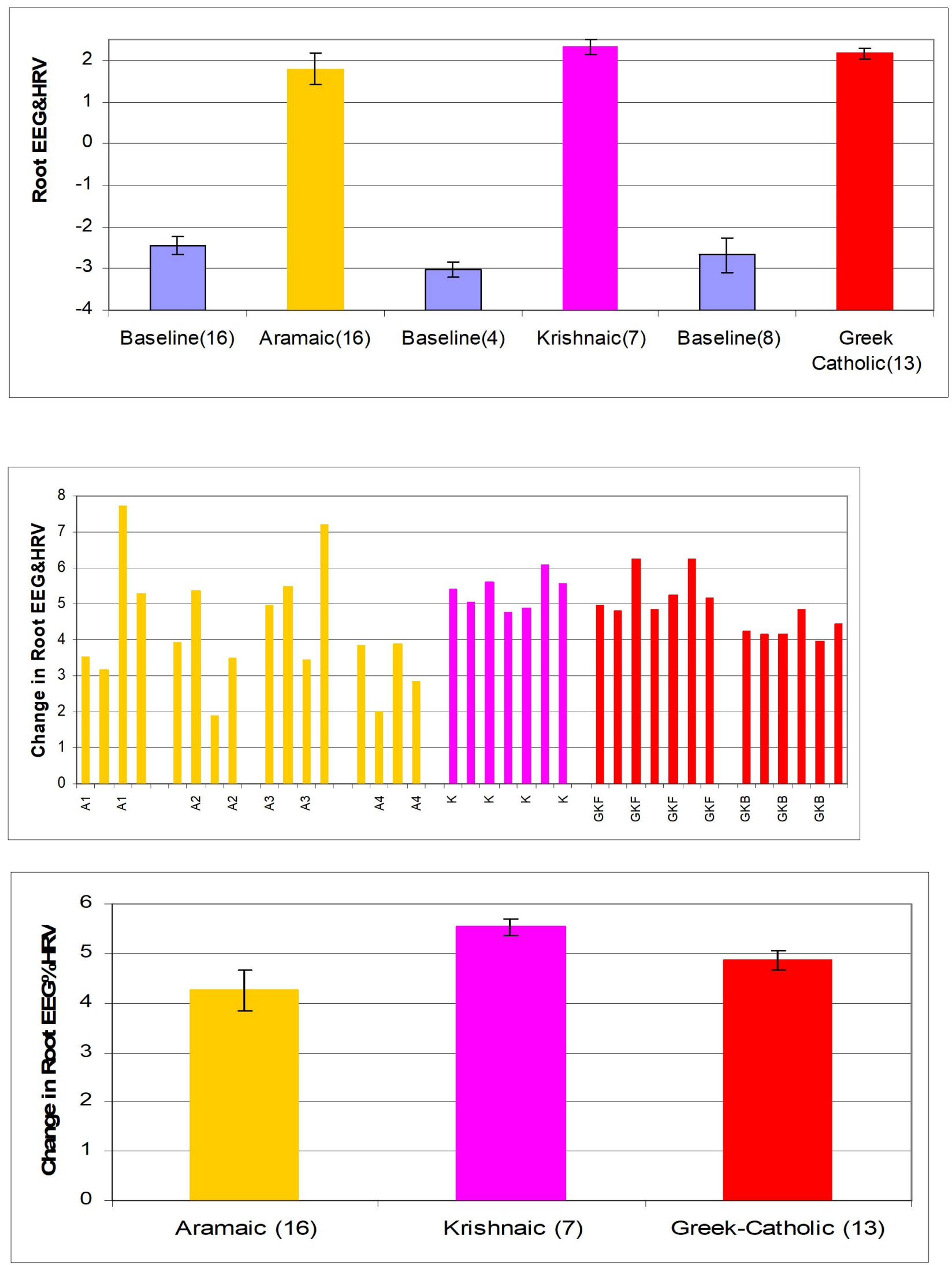

\section{Coefficients and Constants for Classification Functions}

\begin{tabular}{|l|l|l|}
\hline Variables currently & Baseline & Prayer \\
\cline { 2 - 3 } in the mode & $\mathrm{n}=28$ & $\mathrm{n}=36$ \\
\hline
\end{tabular}




\begin{tabular}{|c|c|c|}
\hline Entropy SPD HRV & 32231 & 31888 \\
\hline LFnu HRV SPD, $\%$ & 49,83 & 48,94 \\
\hline F3- $\alpha$ SPD, $\%$ & $-1,21$ & $-0,97$ \\
\hline$\theta$-rhythm Index, \% & $-3,13$ & $-3,02$ \\
\hline$\delta$-rhythm Asymmetry, \% & 1,64 & 1,39 \\
\hline ULF HRV SPD, \% & $-585,4$ & $-578,0$ \\
\hline Entropy SPD in locus $\mathrm{O} 2$ & 448,6 & 437,1 \\
\hline T4- $\alpha$ SPD, \% & $-6,49$ & $-6,30$ \\
\hline T3- $\theta$ SPD, $\%$ & 17,96 & 18,45 \\
\hline HF HRV SPD, $\%$ & 39,48 & 37,79 \\
\hline AMo HRV, \% & 244,9 & 240,7 \\
\hline SDNN HRV, msec & 162,4 & 158,5 \\
\hline HF HRV SPD, $\mathrm{msec}^{2}$ & $-2,99$ & $-2,80$ \\
\hline ULF HRV SPD, $\mathrm{msec}^{2}$ & 1,80 & 1,75 \\
\hline T6- $\beta$ SPD,$\mu V^{2} / \mathrm{Hz}$ & 0,41 & 0,43 \\
\hline$(\mathrm{VLF}+\mathrm{LF}) / \mathrm{HF}$ & 833,6 & 828,1 \\
\hline Moda HRV, msec & 4,55 & 4,51 \\
\hline Constants & -26347 & -25653 \\
\hline
\end{tabular}

\section{ACKNOWLEDGMENT}

We express sincere gratitude to administration of JSC "Truskavets'kurort" and clinical sanatorium "Moldova" for help in conducting this investigation. Special thanks to Father Volodymyr, Brather Ivan and Viktor.

\section{ACCORDANCE TO ETHICS STANDARDS}

Tests in patients are conducted in accordance with positions of Helsinki Declaration 1975, revised and complemented in 2002, and directive of National Committee on ethics of scientific researches. During realization of tests from all participants the informed consent is got. All participants (Father Volodymyr, Brather Ivan and Viktor) agreed to publish their names.

For all authors any conflict of interests is absent.

\section{REFERENCES}

1. Babelyuk VYe, Dubkowa GI, Korolyshyn TA, Holubinka SM, Dobrovol's'kyi YG, Zukow W, Popovych IL. Operator of Kyokushin Karate via Kates increases synaptic efficacy in the rat Hippocampus, decreases C3- $\theta$-rhythm SPD and HRV Vagal markers, increases virtual Chakras Energy in the healthy humans as well as luminosity of distilled water in vitro. Preliminary communication. Journal of Physical Education and Sport. 2017; 17(1): 383-393.

2. Babelyuk VYe, Dubkova GI, Popovych IL. Influence of meditation on the parameters bioelectrography (kirlianography), heart rate variability and blood pressure [in Ukrainian]. Medical Hydrology and Rehabilitation. 2010; 8(1): 17-23.

3. Babelyuk VYe, Dubkova GI, Popovych IL. Stresslimiting effect of meditation on the human body [in Ukrainian]. In: Materials III scientific-practical conference "Issues of pathology in conditions of extreme factors action on the body" (Ternopil, 4-5 November 2010): Achievements of Clinical and Experimental Medicine. 2010; 2(13): 117-118.

4. Baevskiy RM, Ivanov GG. Heart Rate Variability: theoretical aspects and possibilities of clinical application [in Russian]. Ultrazvukovaya i funktsionalnaya diagnostika. 2001; 3: 106-127.

5. Barylyak LG, Tsymbryla VV, Zukow W, Popovych IL. Relationships between parameters of plasma lipoproteines profile and heart rate variability. Journal of Education, Health and Sport. 2019; 9(12): 238-253. 
6. Berntson GG, Bigger JT jr, Eckberg DL, Grossman P, Kaufman PG, Malik M, Nagaraja HN, Porges SW, Saul JP, Stone PH, Van der Molen MW. Heart Rate Variability: Origines, methods, and interpretive caveats. Psychophysiology. 1997: 34; 623-648.

7. Cahn BR, Polish J. Psychological bulletin meditation states and traits: EEG, ERP and neuroimaging studies. Psychol. Bull. 2006; 132: 180-211.

8. Doufesh H, Faisal T, Lim KS, Ibrahim F. EEG spectral analysis of Muslim Prayers. Appl Psychophysiol Biofedback. 2012; 37(1): 11-18.

9. Doufesh H, Ibrahim F, Ismail NA, Ahmad WAW. Effect of Muslim Prayer (Salat) on $\alpha$ Electroencephalography and Its Relationship with Autonomic Nervous System Activity. J Altern Complement Med. 2014; 20(7): 558-562.

10. Doufesh H, Ibrahim F, Safari M. Effects of Muslims Praying (Salat) on Electroencephalography gamma activity. Complement Ther Clin Pract. 2016; 24: 6-10.

11. Gao j, Front Psychol. 2017; 7: 2055.

12. Gao j,Scientific Reports. 2019; 9: 4262.

13. Gozhenko AI, Hrytsak YL, Barylyak LG, Kovbasnyuk MM, Tkachuk SP, KorolyshynTA, Matiyishyn GY, Zukow W, Popovych IL. Features of immunity by various constellations of principal adaptation hormones and autonomous regulation in practically healthy people. Journal of Education, Health and Sport. 2016; 6(10): 215-235.

14. Heart Rate Variability. Standards of Measurement, Physiological Interpretation, and Clinical Use. Task Force of ESC and NASPE. Circulation. 1996; 93(5): 1043-1065.

15. Khaspekova NB. Diagnostic informativeness of monitoring HRV [in Russian]. Vestnik aritmologii. 2003. 32: 15-23.

16. Klecka WR. Discriminant Analysis [trans. from English in Russian] (Seventh Printing, 1986). In: Factor, Discriminant and Cluster Analysis. Moskva. Finansy i Statistika; 1989: 78-138.

17. Korkushko OV, Pysaruk AV, Shatylo VB. The value of heart rate variability analysis in cardiology: age aspects [in Russian]. Circulation and Hemostase. 2009; 1-2: 127-139.

18. Kotelnikov SA, Nozdrachov AD, Odinak MM, Shustov EB, Kovalenko IYu, Davidenko VYu. Heart rate variability: understanding of the mechanisms [in Russian]. Fiziologiya cheloveka. 2002; 28(1): 130-143.

19. Kul'chyns'kyi AB, Gozhenko AI, Zukow W, Popovych IL. Neuro-immune relationships at patients with chronic pyelonephrite and cholecystite. Communication 3. Correlations between parameters EEG, HRV and Immunogram. Journal of Education, Health and Sport. 2017; 7(3): 53-71.

20. Kul'chyns'kyi AB, Kovbasnyuk MM, Kyjenko VM., Zukow W, Popovych IL. Neuro-immune relationships at patients with chronic pyelonephrite and cholecystite. Communication 2. Correlations between parameters EEG, HRV and Phagocytosis. Journal of Education, Health and Sport. 2016; 6(10): 377-401.

21. Kul'chyns'kyi AB, Kyjenko VM, Zukow W, Popovych IL. Causal neuro-immune relationships at patients with chronic pyelonephritis and cholecystitis. Correlations between parameters EEG, HRV and white blood cell count. Open Medicine. 2017; 12(1): 201-213.

22. Kul'chyns'kyi AB, Zukow W, Korolyshyn TA, Popovych IL. Interrelations between changes in parameters of HRV, EEG and humoral immunity at patients with chronic pyelonephritis and cholecystitis. Journal of Education, Health and Sport. 2017; 7(9): 439-459.

23. Lee DJ, Kulubya E, Goldin Ph, Goodarzi A, Girgis F. Review on the neural oscillation underlying Meditation. Front Neurosci. 2018; 12: 178.

24. Matthews SC, Paulus MP, Simmons AN et al. Functional subdivision with anterior cingulate cortex and their relationship to autonomic nervous system function. Neuroimage. 2004; 22(3): 1151-1156.

25. Newberg AB, Waldman MR. How God Change Your Brain: Breakthrough Findings from a Leading Neuroscientist. NY; 2009: 324 p.

26. Osama M, Malik RJ. Salat (Muslim Prayer) as a therapeutic exercise. J Pak Med Assoc. 2019; 69(3): 399-404.

27. Panday KP, Panday DR. Heart Rate Variability (HRV)/ J Clin Exp Cardiol. 2018; 9(4): 583.

28. Popadynets' O, Gozhenko A, Badyuk N, Popovych I, Skaliy A, Hagner-Derengowska M, Napierata M, Muszkieta R, Sokołowski D, Zukow W, Rybałko L. Interpersonal differences 
caused by adaptogen changes in enropies of EEG, HRV, immunocytogram, and leukocytogram. Journal of Physical Education and Sport. 2020; 20(Suppl. 2): 982-999.

29. Popadynets' OO, Gozhenko AI, Badiuk NS, Zukow W, Kovbasnyuk MM, Korolyshyn TA, Popovych IL. Relationships between changes in entropy of the EEG and parameters of the immunity. Pedagogy and Psychology of Sport. 2020; 6(1): 24-40.

30. Popadynets' OO, Gozhenko AI, Zukow W, Popovych IL. Relationships between the entropies of EEG, HRV, immunocytogram and leukocytogram. Journal of Education, Health and Sport. 2019; 9(5): 651-666.

31. Popovych IL. The concept of neuro-endocrine-immune complex (Review) [in Russian]. Medical Hydrology and Rehabilitation. 2009; 7(3): 9-18.

32. Popovych IL, Babelyuk VYe, Gozhenko AI, Zukow W, Zubow PG, Dubkova GI, Korolyshyn TA, Nesterova LF, Barylyak LG. Holy water changes EEG and HRV because of autosuggestion and his information (God Grace, World Mind, Cosmic Energy etc). Journal of Education, Health and Sport. 2015; 5(1): 203-220.

33. Popovych IL, Babelyuk VYe, Korolyshyn TA, Dubkova GI. The immediate influence of Christian Prayer on parameters of the electroencephalogram and kirlianogram [in Ukrainian]. In: Materials VI scientific-practical conference "Issues of pathology in conditions of extreme factors action on the body" (Ternopil, 31 October - 1 November 2012): Achievements of Clinical and Experimental Medicine. 2013; 2(19): 275-276.

34. Popovych IL, Babelyuk VYe, Zukow W, Muszkieta R, Dubkova GI, Nesterova LF, Hubyts'kyi VY, Bilas VR, Musienko VY, Seniv TS, Mis'ko VT, Babylyuk RV, Yaremchuk YM, Barylyak LG, Zukow W, Gozhenko AI. Liturgy affects the parameters of gas discharge visualization, acupuncture points and neuro-endocrine-immune complex. Pedagogy and Psychology of Sport. 2020; 6(2): 61-73.

35. Popovych IL, Korolyshyn TA. Christian prayer immediately changes the parameters of EEG [in Ukrainian]. In: Materials Sciences Conf. "Information technology in neurology, psychiatry, epileptology and medical statistics" (Kyiv, 17-18 October 2013). Clin Inform Telemed. 2014; 10: 176-177.

36. Popovych IL, Korolyshyn TA, Zubov PG. Neurotropic effect of Holy Water [in Ukrainian]. In: Materials scientific conference "Kurortology: Modern rehabilitation medicine achievements and prospects" (Ternopil', 8-9 oktober 2014): Medical Rehabilitation, Kurortology, Physiotherapy. 2014; 3(Suppl.): 93-94.

37. Popovych IL, Kozyavkina OV, Kozyavkina NV, Korolyshyn TA, Lukovych YuS, Barylyak LG. Correlation between Indices of the Heart Rate Variability and Parameters of Ongoing EEG in Patients Suffering from Chronic Renal Pathology. Neurophysiology. 2014; 46(2): 139148.

38. Popovych IL, Kul'chyns'kyi AB, Gozhenko AI, Zukow W, Kovbasnyuk MM, Korolyshyn TA. Interrelations between changes in parameters of HRV, EEG and phagocytosis at patients with chronic pyelonephritis and cholecystitis. Journal of Education, Health and Sport. 2018; 8(2): 135-156.

39. Popovych IL, Kul'chyns'kyi AB, Korolyshyn TA, Zukow W. Interrelations between changes in parameters of HRV, EEG and cellular immunity at patients with chronic pyelonephritis and cholecystitis. Journal of Education, Health and Sport. 2017; 7(10): 11-23.

40. Popovych I.L., Lukovych Yu.S., Korolyshyn T.A., Barylyak L.G., Kovalska L.B., Zukow W. Relationship between the parameters heart rate variability and background EEG activity in healthy men. Journal of Health Sciences. 2013; 3(4): 217-240.

41. Prinsloo GE, Rauch HG, Karpul D, Derman WE. The effect of a Single Session of Short Duration Heart Rate Variability Biofeedback on EEG: A Pilot Study. Appl. Psychophysiol. Biofeedback. 2013; 38(1): 45-56.

42. Romodanov AP (editor). Postradiation Encephalopathy. Experimental Researches and Clinical Observations [in Ukrainian and Russian]. Kyiv. USRI of Neurosurgery; 1993: 224 p.

43. Shannon CE. Works on the theory of informatics and cybernetics [transl. from English to Russian]. Moskwa: Inostrannaya literatura; 1963: $329 \mathrm{p}$.

44. Slezin VB, Muzalevskaya NI, Uritskiy VM, Rybina IYa. Changing the functional state of the brain in Christian prayer [in Russian]. // http://altheo-club.ru/ 
45. Steinhubl SR, Wineigner NE, Patel Sh, Boeldt DL, Mackellar G, Porter V, Redmond JD, Muse ED, Nicholson L, Chopra D, Topol EJ. Cardiovascular and nervous system changes during meditation. Front Hum Neurosci. 2015; 9:145.

46. Tang YY, Ma Y, Fan Y et al. Central and autonomic nervous system interaction is altered by short-term meditation. Proc. Natl. Acad. Sci. USA. 2009; 106(22): 8865-8870.

47. Vaghefi M, Nasrabadi AM, Golpayegani SMRH, Mohammadi MR, Gharibzadeh Sh. Nonlinear analyzing of EEG signals while listening to the Holy Quran. J Med Signals Sens. 2019; 9(2): 100-110.

48. Winkelmann T, Thayer JF, Pohlak ST, Nees F, Grimm O, Flor H. Structural brain correlates of heart rate variability in healthy young adult population. Brain Structure and Function. 2017; 222(2): 1061-1068.

49. Yoo HJ, Thayer JF, Greenig S, Lee TH, Ponzio A, Min J, Sakaki M, Nga L, Mater M, Koenig J. Brain structural concomitants of resting state heart rate variability in the young and old: evidence from two independent samples. Brain Structure and Function. 2018; 223(2): 727737.

50. Yousefzadeh F, Jahromi GP, Manshadi EM, Hatef B. The effect of prostration (Sajdah) on the prefrontal brain activity: A pilot study. Basic and Clinical Neuroscience. 2019; 10(3): 257268.

51. Yushkovs'ka OG. Using information theory to study adaptive responses in the body athletes [in Ukrainian]. Medical Rehabilitation, Kurortology, Physiotherapy. 2001; 1(25): 40-43.

52. Zukow W, Popadynets' OO, Gozhenko AI, Popovych IL. Interpersonal differences in parameters of the EEG and HRV in the humans with various levels of the entropy of the EEG, HRV, immunocytogram and leukocytogram. Journal of Education, Health and Sport. 2019; 9(7): 448-466. 